\title{
Estimating the economic impact of the permafrost carbon feedback
}

\author{
Louise Kessler \\ December 2015
}

Centre for Climate Change Economics and Policy Working Paper No. 246

Grantham Research Institute on Climate Change and the Environment Working Paper No. 219 
The Centre for Climate Change Economics and Policy (CCCEP) was established by the University of Leeds and the London School of Economics and Political Science in 2008 to advance public and private action on climate change through innovative, rigorous research. The Centre is funded by the UK Economic and Social Research Council. Its second phase started in 2013 and there are five integrated research themes:

1. Understanding green growth and climate-compatible development

2. Advancing climate finance and investment

3. Evaluating the performance of climate policies

4. Managing climate risks and uncertainties and strengthening climate services

5. Enabling rapid transitions in mitigation and adaptation

More information about the Centre for Climate Change Economics and Policy can be found at: http://www.cccep.ac.uk.

The Grantham Research Institute on Climate Change and the Environment was established by the London School of Economics and Political Science in 2008 to bring together international expertise on economics, finance, geography, the environment, international development and political economy to create a worldleading centre for policy-relevant research and training. The Institute is funded by the Grantham Foundation for the Protection of the Environment and the Global Green Growth Institute. It has nine research programmes:

1. Adaptation and development

2. Carbon trading and finance

3. Ecosystems, resources and the natural environment

4. Energy, technology and trade

5. Future generations and social justice

6. Growth and the economy

7. International environmental negotiations

8. Modelling and decision making

9. Private sector adaptation, risk and insurance

More information about the Grantham Research Institute on Climate Change and the Environment can be found at: http://www.Ise.ac.uk/grantham.

This working paper is intended to stimulate discussion within the research community and among users of research, and its content may have been submitted for publication in academic journals. It has been reviewed by at least one internal referee before publication. The views expressed in this paper represent those of the author(s) and do not necessarily represent those of the host institutions or funders. 


\title{
Estimating the economic impact of the permafrost carbon feedback
}

\author{
Louise Kessler \\ ESRC Centre for Climate Change Economics and Policy \\ Grantham Institute on Climate Change and the Environment \\ Department of Geography and Environment \\ London School of Economics and Political Science
}

December 2015

\begin{abstract}
The permafrost carbon feedback is not currently taken into account in economic assessments of climate change, yet it could have important implications for the social cost of carbon and the associated choice of the optimal greenhouse gas emissions pathway. Although this feedback is still imperfectly known, there are enough estimates of its potential strength to now include it in our assessments. In this paper, I present a model of the permafrost carbon feedback and integrate it in the DICE Integrated Assessment Model to examine its consequences. I find that doing so increases the social cost of carbon by $10-20 \%$ in the base case scenario, but that this impact is much more significant in the case of a more convex damage function and can reach up to $220 \%$. It follows that setting industrial emissions targets without taking into account the permafrost carbon feedback would lead to excessive atmospheric carbon: I find that it increases the optimal emissions rate by c. 8 percentage points on average over the period 2015-2100. These results are yet another illustration of the crucial role of discounting and damage functions in economic assessments of climate change but also make a clear case for including the permafrost carbon feedback in the current debate about the appropriate stringency of climate mitigation commitments.
\end{abstract}

Email for correspondence: l.kessler@lse.ac.uk

This Research was supported by the ESRC Centre for Climate Change Economics and Policy, which is funded by the UK Economic and Social Research Council. 


\section{Introduction}

Integrated assessment models (IAMs) are meant to be simple, tractable models which can be readily used to evaluate the costs and benefits of different climate policies. However, the absence of key factors and crucial feedback loops in these models has been highlighted (Stern, 2013), to the point where they were said to render IAMs "close to useless as tools for policy analysis" (Pindyck, 2013). Indeed, IAMs are used for evaluations of policies which can run up to several centuries (IAWG, 2010), despite the fact that the main carbon-climate feedbacks included in IAMs are those which enter through the climate sensitivity parameter, and which correspond primarily to the "fast" feedbacks: namely, water vapour, temperature lapse rate, surface albedo and clouds. Many other feedback processes, such as, for instance, the thawing of permafrost carbon, changes in ocean circulation and the shift of the terrestrial biosphere from a sink to a source of carbon, are not expected to become significant by the end of the $21^{\text {st }}$ century. Still, these could have non-negligible impacts on global mean temperature and climate damages over the next 200 or 300 years, and should be taken into account when assessing the long-term economic implications of climate change. Admittedly, feedback processes are still imperfectly known and the uncertainty pertaining to their strength, scale and timing is wide. However, contrary to climate models which are limited in their ability to incorporate poorly known complex processes, IAMs precisely provide the opportunity to integrate and explore the impact of uncertain processes through the use of stochastic modelling and Monte Carlo simulations.

Research in this area has developed along several dimensions. The first dimension corresponds to studies aimed at assessing the significance of the climate and carbon components of IAMs for climate and economic outcomes (van Vuuren et al., 2011; Marten, 2011; Warren et al., 2010). These have shown that the modelling of climate dynamics could have significant impacts, especially for longer-term horizons, and that the failure to capture climate dynamics correctly could lead to underestimating the benefits of mitigation policies (Hof et al., 2012).

The second line of research has aimed at investigating the economic impact of low-probability, high-damage feedbacks, such as a sudden and significant release of methane into the atmosphere. Ceronsky et al. (2011) considered the impact of three methane release scenarios on the level of climate damages and on the social cost of carbon (SCC); Whiteman, Hope and Wadhams (2013) superposed a pulse of $50 \mathrm{Gt}$ of methane on two standard emissions scenarios in order to assess the risks associated with the potential thawing of methane hydrates from the East Siberian Arctic shelf; finally, Lemoine and Traeger (2014) considered a framework in which multiple tip- 
ping points interact and represented the possibility that large methane stores locked in permafrost and in ocean shallow clathrates are mobilized by warming by an increase of the equilibrium climate sensitivity parameter from $3{ }^{\circ} \mathrm{C}$ to $5^{\circ} \mathrm{C}$.

The third line of research has focused on exploring economic and physical uncertainties in IAMs through the use of Monte Carlo methods: Ackerman et al. (2010) explored the implications of varying simultaneously the climate sensitivity parameter and the damage function exponent using the DICE model; Pycroft et al. (2011) conducted a similar exercise using PAGE09; Calel et al. (2013) demonstrated that the uncertainty about the effective heat capacity of the upper ocean mattered significantly for economic evaluations.

Finally, there have been some attempts at improving carbon cycles representation in IAMs. For instance, Glotter et al. (2014) have proposed a modification of the carbon cycle in DICE to reflect the nonlinear $\mathrm{CO}_{2}$ uptake of the ocean.

The realization that the permafrost carbon feedback is potentially the most important positive feedback on policy-relevant time scales that is currently not included in Earth System Models (Prentice et al., 2015) and that it will very likely act as an amplifier of human-induced climate change, and, as such, it could represent significant costs to society, has led to an increase in the attention that this topic is receiving. Indeed, several articles have been published very recently that testify to the growing interest for this topic both from a physical and an economic perspective. Schuur et al. (2015) provided an overview of the existing research on the permafrost carbon feedback with the aim of refining our understanding of its sensitivity to climate. Hope and Schaefer (2015) linked the PAGE09 economic model with the SiBCASA land surface model to examine the economic impact of carbon emissions from thawing permafrost under the A1B scenario from IPCC (Nakicenovic and Swart, 2000) and estimated that carbon emissions from permafrost increases the mean net present value of the impacts of climate change by about $13 \%$. Koven et al. (2015b) presented a simplified approach for estimating the strength of the permafrost carbon feedback, based on a data-constrained approach, to measure the global sensitivity of frozen soil carbon to climate change on a 100 year time scale.

This paper thus proposes to complement this growing literature and to provide an estimate of the economic impact of the permafrost carbon feedback in the framework of the most widely used integrated assessment model, DICE, and to explore its potential impact in terms of additional warming, damages and consumption losses. Rather than an exercise in climate mod- 
elling, this paper aims at answering the following questions: given what we know and what we don't know about the potential strength and timing of the permafrost carbon feedback, how does it impact our cumulative emissions targets and our estimates of the social cost of carbon? How does it affect the projected time horizon at which we will reach the $+2{ }^{\circ} \mathrm{C}$ threshold? How does it change the scale of climate-induced risks that we face? And how can we compare the current uncertainty on the permafrost carbon feedback with the uncertainty on other physical and economic processes? If the permafrost carbon feedback is expected to make climate change happen faster than we project on the basis of human activities alone, then it is essential to integrate it into the tools used to design and evaluate climate change mitigation policies.

This paper is organized as follows: in Section 2, I will first briefly describe what is referred to as the "permafrost carbon feedback" and provide estimates of its projected strength. In section 3, I will introduce the methodology I used to integrate it into DICE-2013R. In Section 4, I will present some results, in terms of the impact of the permafrost carbon feedback both on the social cost of carbon and on the optimal abatement path, under different assumptions and conditions. Finally, in Section 5 I will compare these results with previous ones and discuss some potential limitations of the model.

\section{What is the permafrost carbon feedback and how have its potential economic impacts been assessed so far?}

\subsection{General overview of the permafrost carbon feedback}

Permafrost is defined as perennially frozen ground remaining at or below $0{ }^{\circ} \mathrm{C}$ for at least two consecutive years (Brown et al., 1997). It is composed of bedrock, gravel, silt and organic material that was buried and frozen during or since the last ice age (Schaefer et al., 2014) and it occurs in about $24 \%$ of the exposed land surface in the Northern Hemisphere (Schaefer et al., 2012), mainly in Siberia, Greenland and Northern Canada. Because organic matter does not decay once the soil is frozen, it is only when temperatures rise, causing permafrost to thaw, that the organic matter starts to decay, releasing carbon dioxide $\left(\mathrm{CO}_{2}\right)$ and methane $\left(\mathrm{CH}_{4}\right)$ into the atmosphere, which further amplifies the warming due to greenhouse gas emissions. The permafrost carbon feedback (PCF) is this amplification of anthropogenic warming due to carbon emissions from thawing permafrost, and like emissions of greenhouse gases from fossil fuel burning, it is irreversible on human time scales (Figure 1). 
Figure 1: Dynamics of the permafrost carbon feedback

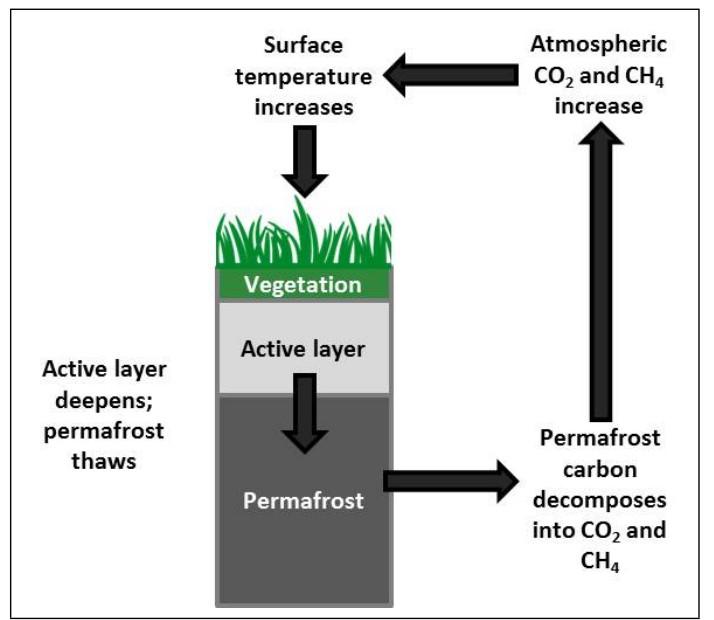

One of the characteristics of the PCF lies in the fact that there is a significant time lag between the trigger (global temperature increase) and the response $\left(\mathrm{CO}_{2}\right.$ release into the atmosphere). This means that even if the amount of permafrost carbon that is expected to be released by 2100 is limited, the impact that the permafrost carbon feedback will have in the $22^{\text {nd }}$ and $23^{\text {rd }}$ centuries will be partly determined by the level of warming during the 21st century, and therefore, by the mitigation policies implemented at that time. As emphasized by Schneider von Deimling et al. (2012), "even more pronounced than many other components of the Earth system, the permafrost feedback highlights the lagged and slow response to human perturbations". Schaefer et al. (2011) show that, for the SRES A1B emissions scenario, $80-90 \%$ of the thawing of permafrost carbon occurs before 2100 , but $46 \%$ of the thawed carbon is released into the atmosphere after warming stops in 2100. According to the recent meta-analysis by Schaefer et al. (Schaefer et al., 2014), long-term estimates indicate that $60 \%$ of the permafrost emissions will occur after 2100 .

Another attribute of the PCF is that it is extremely likely to be positive (i.e. it will amplify climate change): although it might trigger some negative feedbacks (e.g. enhanced plant growth) that will dampen global warming, the uncertainty on the PCF is said to be "one-sided" in the sense that it will increase future climate impacts (Schneider von Deimling et al., 2012). The PCF will therefore add to other existing positive carbon-climate feedbacks (e.g. water vapour, temperature lapse rate, surface albedo, etc.) and 
as a result, the total effect of these feedbacks will be larger than the sum of the individual impacts. This "compounding effect" of positive feedbacks has been demonstrated by Roe (2009), who showed that the amplitude of the additional radiative perturbation that one positive feedback produces is amplified by the enhanced system response (i.e., the increased warming) the other has created, thus making the total system response even larger.

There are many different aspects in which the inclusion of positive longterm feedbacks such as the PCF is indispensable for the economic assessment of mitigation policies. Firstly, in the context of the classical approach of marginal costs and benefits analysis, adding the PCF in a climate-economy model is likely to have an impact on estimates of the social cost of carbon i.e., the net present value of the marginal benefit of mitigation. Secondly, climate policies are often expressed in terms of $\mathrm{CO}_{2}$ concentration targets, which makes the inclusion of the PCF even more relevant, as accounting for its effects will almost certainly increase the emissions reductions required to reach these targets (Schuur et al., 2013). This cut in allowable emissions could be non-negligible and has been estimated by Schaefer et al. (2011) to be roughly $14 \%$ ( $\pm 5 \%$ ) for a target $\mathrm{CO}_{2}$ concentration of 700 ppm. Finally, if the $\mathrm{PCF}$ is projected to make climate change happen faster than expected on the basis on anthropogenic emissions alone, then it will also have significant implications for the timing of adaptation strategies.

\subsection{Estimates of the projected strength of the permafrost carbon feedback}

According to the estimation of the size of the permafrost carbon pool provided by Tarnocai et al. (2009), the area of all soils in the northern permafrost region represents $16 \%$ of the global soil area and 1,024 Gt of carbon can be found in the top $3 \mathrm{~m}$ of soil whereas $648 \mathrm{Gt}$ is frozen in deposits known to extend below $3 \mathrm{~m}$. In total, the northern permafrost region contains approximately 1,672 Gt of organic carbon, of which approximately 1,466 Gt, or $88 \%$, occurs in perennially frozen soils and deposits. More recent estimates (Hugelius et al., 2014; Schuur et al., 2015) found that the northern near-surface carbon pool (0-3m) should be around 1,035 $\pm 150 \mathrm{Gt}$ of carbon (95\% confidence interval). Adding up estimates of the deep carbon in the yedoma region and river deltas brings the known pool of terrestrial carbon in the northern permafrost zone to 1,330-1,580 GtC, with the potential for c. $400 \mathrm{GtC}$ in other deep terrestrial permafrost sediments that remain largely unquantified (Schuur et al., 2015). The total carbon content of the permafrost region thus represents roughly twice the amount of $\mathrm{CO}_{2}$ currently in the atmosphere (c. $850 \mathrm{GtC}$ ). 
As noted by Schuur et al. (2013), the perception of the importance of the PCF to climate change has been dominated by the improved quantification of the size of the permafrost carbon pool, whereas the strength of this feedback will be primarily determined by the amount that is vulnerable to release, the speed at which it will be released, and whether it will be released as $\mathrm{CO}_{2}$ or $\mathrm{CH}_{4}$.

According to the IPCC's Fifth Assessment Report (2013), despite the fact that none of the models participating in C4MIP or CMIP5 includes explicit representation of permafrost soil carbon decomposition in response to future warming, including these processes in an Earth System Model may change the sign of the high northern latitude carbon cycle response to warming from a sink to a source. Indeed, as stated in the report, there is high confidence that reductions in permafrost extent due to warming will cause thawing of some currently frozen carbon, but there is low confidence on the magnitude of the flow of carbon through carbon dioxide and methane emissions to the atmosphere. The overall magnitude of $\mathrm{CO}_{2}$ and $\mathrm{CH}_{4}$ emissions to the atmosphere is assessed to range from 50 to $250 \mathrm{GtC}$ between 2000 and 2100 for RCP8.5, which corresponds to the highest of the four concentration scenarios defined by the IPCC (2013).

Several estimates of the impacts of the PCF on the global climate have been published. Schaefer et al. (2014) published a meta-analysis in 2014, and there have been a few more studies published since (Schneider von Deimling et al., 2014; Schuur et al., 2015). It is worth noting that, except for those from MacDougall et al. (2012) and Schneider von Deimling et al. $(2012 ; 2014)$, none of the projections represents the complete or closed feedback loop on global temperature, where emissions from thawing permafrost influence air temperature and the simulated permafrost thaw rate. Therefore, open-loop estimates need to be integrated in a dynamic model in order to represent the full potential impact of the PCF. According to the study by MacDougall et al. (2012) permafrost carbon emissions could constitute $190 \mathrm{GtC}$ by 2100 and $800 \mathrm{GtC}$ by 2300 ; a more recent study by Schneider et al. (2014) assesses that permafrost carbon emissions could reach $141 \mathrm{GtC}$ by 2100 and $313 \mathrm{GtC}$ by 2300 in the highest warming scenario (RCP8.5).

Obviously, the ultimate radiative forcing potential of permafrost emissions will depend on whether the carbon is released as carbon dioxide $\left(\mathrm{CO}_{2}\right)$ or as methane $\left(\mathrm{CH}_{4}\right)$, as methane has around 25 times the global warming potential of $\mathrm{CO}_{2}$ over a century time scale (Solomon et al., 2007). Only a few studies provide estimates of the proportion of thawed carbon that will be released as methane. According to the IPCC's Fifth Assessment Report (2013), hydrological changes may lead to trade-offs between the $\mathrm{CO}_{2}$ and $\mathrm{CH}_{4}$ balance of ecosystems underlain by permafrost, with methane produc- 
tion rates being roughly an order of magnitude less than rates of decomposition to $\mathrm{CO}_{2}$. However, the IPCC pinpoints that, although the extent of permafrost thaw simulated by climate models has been used to estimate possible subsequent carbon release, few studies explicitly partition this into $\mathrm{CO}_{2}$ or $\mathrm{CH}_{4}$ release to the atmosphere. Based on the results of the survey by Schuur et al.(2013), the proportional release of $\mathrm{CH}_{4}$ estimated by experts was relatively invariant across all warming scenarios and time horizons at about 2.3\%. Schneider von Deimling et al. (2012) find a similar range in their simulations, with methane emissions accounting for approximately $1 \%$ to $3 \%$ of the total carbon release, which constitutes cumulative $\mathrm{CH}_{4}$ emissions by 2100 between 131 and $533 \mathrm{TgCH}_{4}$ across the 4 RCPs.

The main sources of uncertainty about the permafrost carbon feedback therefore include the size of the permafrost carbon pool, the physical thawing and decomposition rates, as well as the fraction of thawed carbon that will decompose to $\mathrm{CO}_{2}$ or $\mathrm{CH}_{4}$. Other sources of uncertainty not considered for the purpose of this paper include possible mitigating nutrient feedbacks and the role of fine-scale processes such as spatial variability in permafrost degradation (IPCC, 2013).

\section{Proposed methodology - How can we model the permafrost carbon feedback in DICE-2013R}

We decided to use the DICE model as the framework for our analysis of the impacts of the PCF, as it is one of the most well-known IAMs, and one which has often been used to provide estimates of the SCC. A full description of the equations and parameters of the 2013R version is available in Nordhaus and Sztorc (2013).

\subsection{How are climate feedbacks usually characterized?}

Carbon-climate feedbacks usually appear in IAMs as components of the equilibrium climate sensitivity parameter. However, since the permafrost carbon feedback does not feature in the C4MIP and CMIP5 model ensembles, it is not included in the estimate of the equilibrium climate sensitivity $^{1}$ that is provided by the IPCC's Fifth Assessment Report, and which is used in DICE to characterize the Earth system's response (the change in global mean temperature) to a doubling of $\mathrm{CO}_{2}$ concentration. One of the possibilities would therefore be to simply add the impact of the permafrost carbon feedback to this estimate. However, as highlighted by Gregory et al. (2009), individual feedbacks are not additive in their effect on temperature and therefore, the impact of the PCF cannot be estimated separately from 
the equilibrium climate sensitivity parameter and then added back to the estimate.

One of the metrics which has been commonly used for feedbacks is to define climate feedbacks in GtC.K ${ }^{-1}$ (Friedlingstein et al., 2006). However due to the considerable time lag between the thawing of permafrost and its actual release, the flux of permafrost that is released into the atmosphere at time $(\mathrm{t})$ does not depend on the surface temperature at time $(\mathrm{t})$ but on the temperature path over the previous decades/centuries. Schneider von Deimling et al. (2012) precisely point out the limitations of the "carbon pool sensitivity" indicator in the case of the PCF, as cumulative carbon releases per degree of warming are not a scenario- or time-independent characteristic: "carbon fluxes by 2300 are not only a consequence of permafrost thaw in the $23^{\text {rd }}$ century but are also affected by emissions from soil thawed earlier in the $21^{\text {st }}$ and $22^{\text {nd }}$ century" (p.657).

For their assessment of the impact of climate feedbacks on the optimal carbon tax, Lemoine and Traeger (2014) made the choice of a tipping point framework. This does not seem like the most relevant modelling framework for the purpose of this paper as, despite potentially significant carbon emissions from thawing permafrost, anthropogenic fossil fuel emissions are likely to remain the main source of carbon emissions (Schuur et al., 2013). Current research (Schuur et al., 2015) supports the idea of a gradual and prolonged release of permafrost carbon emissions in a warming climate, which would mean that carbon dioxide release from permafrost carbon pools is more likely to act as an accelerator of climate change rather than a tipping point mechanism $^{2}$. In other words, it is likely that carbon emissions from permafrost will make climate change happen faster than expected and therefore, there is a significant risk that temperature targets will be significantly harder to achieve than is currently assessed by the IPCC. As emphasized by Schuur et al. (2015), "although never likely to overshadow emissions from fossil fuels, each additional ton of carbon released from the permafrost region to the atmosphere will probably incur additional costs to society".

\footnotetext{
${ }^{1}$ Climate sensitivity is defined as the equilibrium change in global mean temperature $\left(\Delta T_{2 \mathrm{x}}\right)$ that results from a radiative forcing $\left(\Delta F_{2 \mathrm{x}}\right)$ corresponding to a doubling of atmospheric $\mathrm{CO}_{2}$ concentration (van Vuuren et al., 2011). This response $\Delta T_{2 \mathrm{x}}=\Delta T_{2 \mathrm{x}} / \alpha$ is inversely proportional to the parameter $\alpha$, where $\alpha$ is a measure of the strength of the feedback processes in the system. Therefore, the equilibrium climate sensitivity is an aggregated measure of how the climate responds to an increase in raditive forcing.

${ }^{2}$ According to Schuur et al. (2015), "increased permafrost carbon emissions in a warming climate are more likely to be gradual and sustained rather than abrupt and massive". However, the authors also acknowledge that new regional research is beginning to reveal that a large fraction of permafrost carbon may be vulnerable to abrupt thaw - see the part on "Reasons for potential underestimation of the strength of the PCF".
} 


\subsection{A two-phase approach to modelling the PCF}

Most studies that provide estimates of potential permafrost carbon release over the coming centuries present their results in the following way: they give the total cumulative permafrost carbon released into the atmosphere by a specific date (e.g. 2100, 2200 or 2300) for a specific atmospheric $\mathrm{CO}_{2}$ concentration scenario, namely, one of the four Representative Concentration Pathways $(\mathrm{RCPs})^{3}$. Such a characterization is ill-suited to dynamic models such as DICE, in which emissions at time $(t)$ depend on atmospheric $\mathrm{CO}_{2}$ concentration at time $(t-1)$ : indeed, the concentration of atmospheric $\mathrm{CO}_{2}$ impacts directly global mean temperature and consequently climate damages, which then weigh on the level of output and emissions. Moreover, using a characterization of the PCF in which emissions from permafrost carbon are solely a function of atmospheric $\mathrm{CO}_{2}$ concentration or global mean surface temperature would not allow us to explore the different uncertainties attached to the underlying processes of the PCF. Indeed, if the warming scenario is one of the major uncertainties, there are numerous other uncertainties to explore ${ }^{4}$. Finally, such an over-simplistic representation of permafrost carbon release would bypass the different geological, hydrological and climatic processes at stake.

Hence, what we need is a characterisation of permafrost carbon release which is based on an accurate representation of the processes involved, but which is also suitable for inclusion in DICE-2013R, and tractable enough to explore different types of uncertainties. The majority of the published articles that aim to describe and quantify permafrost carbon release use a two-phase approach; permafrost degradation (or thawing), followed by decomposition of thawed (or vulnerable) permafrost and release into the atmosphere as $\mathrm{CO}_{2}$ or $\mathrm{CH}_{4}$. It is worth noting that only the first phase (thawing) is directly dependent on global mean temperature: as surface temperature rises, the active layer thickness increases and the soil carbon which is no longer permanently frozen becomes vulnerable to decomposition. The second phase (decomposition of carbon and release as $\mathrm{CO}_{2}$ or $\mathrm{CH}_{4}$ ) is

\footnotetext{
${ }^{3}$ Representative Concentration Pathways (RCPs) refer to the four possible climate outcomes which have defined by the IPCC based on a review of the literature. They are defined by their total radiative forcing pathway and level by 2100 .

${ }^{4}$ In their uncertainty assessment, Burke et al. (2012) show that by 2100 , about half the spread in the permafrost-induced temperature anomaly is caused by uncertainties in the RCP scenario, a quarter by uncertainties in the soil carbon distribution, an eighth caused by the quality of the soil and an eighth by the parameterisation of the soil decomposition model. Obviously this uncertainty assessment depends on the choice of the representation of the processes involved in permafrost release. For Slater and Lawrence for instance (2013), the two most important variables for permafrost are air temperature and snow depth, whereas for Mishra et al. (2013), projections of permafrost degradation vary widely due to differences in how models represent the effects of soil organic matter and snow on surface thermal conductivity.
} 
principally a function of the type of permafrost soil that is vulnerable to decomposition: as emphasized by Schuur et al. (2008) "on a global basis, microbial decomposition of organic matter is the dominant pathway of carbon return from terrestrial ecosystems to the atmosphere", which is likely to be the case with carbon from thawed permafrost.

The proposed modelling approach described below follows this two-phase approach.

\subsubsection{Phase 1 - Permafrost thawing}

Permafrost thawing occurs when surface temperature is above $0{ }^{\circ} \mathrm{C}$ for part of the year. Its physical representation is based on the modelling of activelayer thickening, which indicates the increasing depth of the seasonal freezethaw cycle. As near-surface soil temperatures increase with global warming, some of the permafrost soil changes phase from ice to water, thus increasing the layer of soil at the surface that thaws seasonally. Any thorough representation of active-layer thickening via heat transfers would therefore need to take into account the variety of landscapes that compose permafrost soils, highly localized hydrological processes and fine-grid projections of climate variables such as surface temperature (including the impact of polar amplification, which is not uniform over all permafrost areas) and precipitation patterns.

Because we are de facto constrained by the limitations of DICE, which is a simple and globally aggregated model, we use a model based on existing estimates of future permafrost thaw, rather than a process-based approach ${ }^{5}$. Our challenge is therefore to find a model for permafrost thaw which is solely dependent on global mean temperature and which can be fitted to the existing estimates of permafrost degradation (Appendix A). We take a similar approach to the one used by Winton et al. (2011) to determine the sensitivity of the Northern Hemisphere sea ice cover to global temperature change and which is based on an OLS regression of $\Delta I$ (the change in sea ice cover) on $\Delta T$ (the change in global mean temperature). Our model specification for permafrost thaw is the following: 


$$
\operatorname{PFthawed}(t)=\beta *\left[T A T M(t)-T A T M\left(t_{0}\right)\right]+\epsilon
$$

where:

- $t_{0}$ corresponds to the year 2000 ;

- PFthawed $(t)$ is the proportion of the permafrost area that has thawed at time t;

$$
\operatorname{PFthawed}(t)=1-\frac{\text { PFarea }(t)}{\text { PFarea }\left(t_{0}\right)}
$$

- $T A T M(t)$ is global mean surface temperature at time $\mathrm{t}$.

Physical validity The model specification we choose for permafrost degradation relies on the following physical assumptions:

- As long as $T A T M(t)=T A T M\left(t_{0}\right)$, the extent of the permafrost area does not change. The underlying assumption is that $T A T M\left(t_{0}\right)$ corresponds to an equilibrium state, in which the extent of permafrost is stable.

- Similarly, we assume that the intensity of permafrost degradation is a linear function of the rise in global mean temperature above the equilibrium temperature $T A T M\left(t_{0}\right)$. The linearity claim seems to be supported by the current knowledge of permafrost dynamics (Schuur et al., 2015).

Statistical validity We estimate the $\beta$ coefficient through pooled OLS, using a two-level cluster procedure (by RCP and by author) for the standard errors. We find a highly significant estimate of $\beta$ of 0.172 with a two-way clustered robust standard error of 0.0261 (Table 1).

\footnotetext{
${ }^{5}$ The major constraints we face in the choice of a suitable representation of permafrost thawing processes are those which arise from the fact that the proposed modelling will be incorporated in DICE, a simple and globally aggregated model. These constraints are manifold: there is no possibility to introduce spatial heterogeneity; the model operates in five-year time steps; and the only climatic variables are global mean surface temperature and atmospheric $\mathrm{CO}_{2}$ concentration. These constraints therefore eliminate de facto any modelling of thawing processes that relies on a zonation of the permafrost zone, or on climatic variables other than global mean surface temperature. Models such as the one proposed by Anisimov et al. (1997) to make projections of changes in active-layer thickness over the Northern Hemisphere for different climate change scenarios by 2050 are therefore inapplicable for the purpose of this paper.
} 
Table 1: Regression results

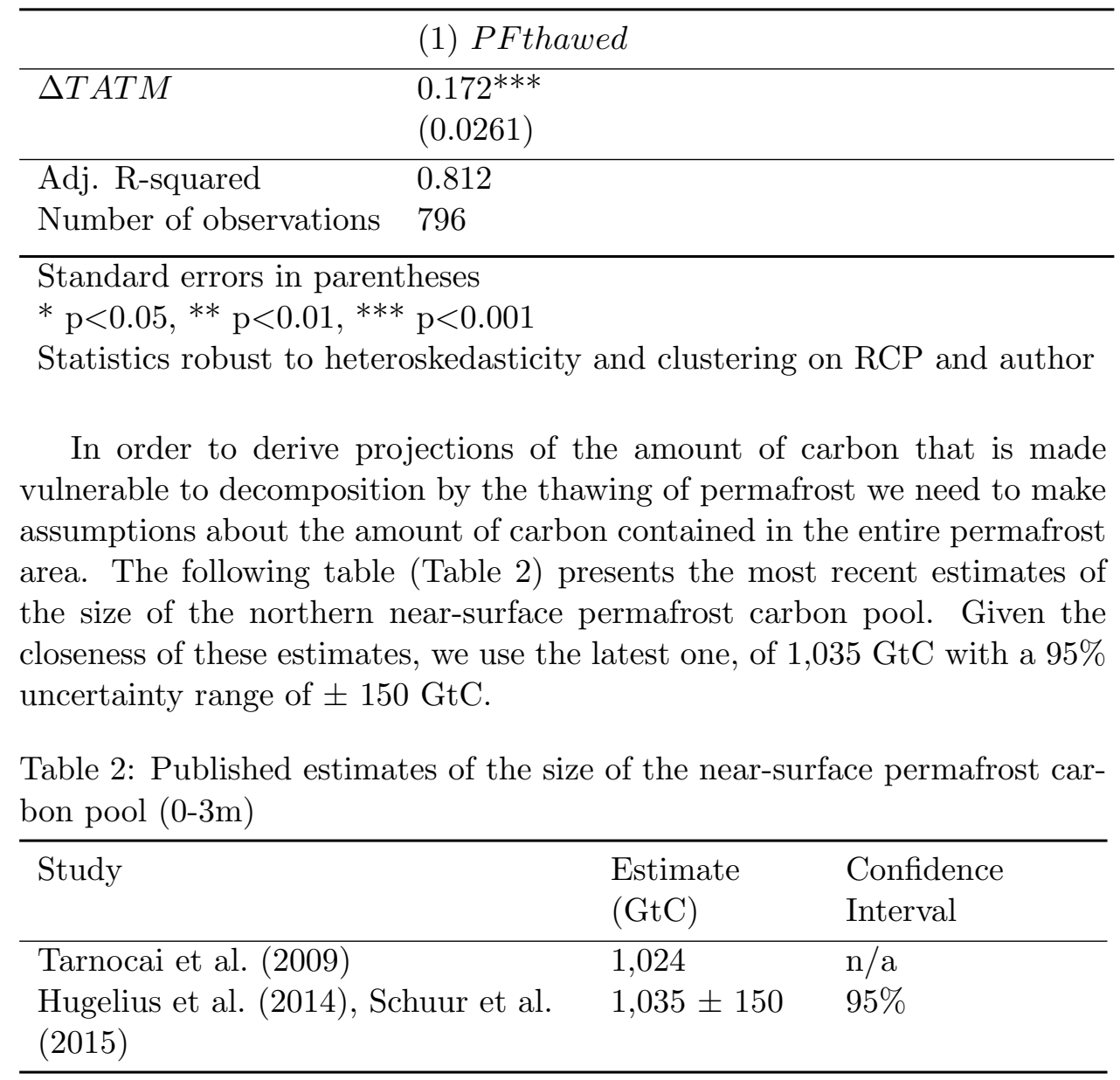

\subsubsection{Phase 2: Carbon decomposition and release as $\mathrm{CO}_{2}$ or $\mathrm{CH}_{4}$}

As mentioned previously, on a global basis, the dominant pathway of carbon return from terrestrial ecosystems to the atmosphere is microbial decomposition (Schuur et al., 2008). The obvious challenge to modelling these processes lies in the fact that permafrost soils across the Northern Hemisphere are highly heterogeneous in their mineral and organic content and, as such, decomposition rates are likely to vary widely.

Many models of permafrost carbon decomposition are based on a partitioning of vulnerable (thawed) permafrost soils into different carbon pools based on their decomposition profiles (Dutta et al., 2006; Schaefer et al., 2011; Burke et al., 2012; Elberling et al., 2013; Schädel et al., 2014).

These representations present two main benefits, namely that they replicate the physical processes at stake and that they do not require a zonation 
of permafrost soils. However, they also present major drawbacks. Firstly, there is not enough data from field and laboratory experiments to allow us to parameterize the different carbon pools (Schädel et al., 2014). Then, climate change will not only increase the amount of carbon which is available for decomposition, but it is also very likely to alter the physical structure and hydrological properties of permafrost soils (Schuur et al., 2009; Zhuang et al., 2009). Therefore, any characterization of permafrost soils is bound to evolve with climate change over the next 300 years. Finally, our choice of representation should reflect the level of the uncertainties at stake: we can try splitting the uncertainty on the decomposition rate into many uncertain parameters and processes but this masks the fact that we really know very little about the rate at which thawed permafrost will decompose over the next 300 years. As emphasized by Schneider von Deimling et al. (2014), the magnitude and timing of carbon fluxes as a consequence of permafrost degradation are highly uncertain.

Therefore, what we propose here is a simplified approach, which conceptually fits the idea that the vulnerable carbon can be divided into a slow, a fast and a passive pool but which does not aim to replicate intricate and evolving microbial decomposition processes. Given the uncertainties surrounding the characterization and mapping of the current permafrost zone, aiming to represent these processes in a dynamic model running over the next 300 years would seem, at best, spurious.

What we need to estimate future emissions of permafrost carbon is to understand the rate at which permafrost carbon will be released into the atmosphere, as well as the form that it will take $\left(\mathrm{CO}_{2}\right.$ or $\left.\mathrm{CH}_{4}\right)$ (Schädel et al., 2014). The approach described here relies on the following assumptions:

- A proportion of the thawed carbon is assumed to be passive, very stable, and not released over the time scale of this study (Burke et al., 2013).

- The decomposition and release of thawed permafrost carbon can be modelled by an exponential decay rate (Schaefer et al., 2011).

Hence, we consider that the main uncertainties pertaining to the decomposition phase are: the size of the passive pool, the rate of decomposition (characterized as the e-folding time) and the proportion of decomposed carbon that will be released as $\mathrm{CH}_{4}$.

Assuming that the decomposition of permafrost carbon follows an exponential decay function, the amount of thawed permafrost carbon that is released at time (t) can therefore be expressed as:

$$
\text { decompC }(t)=\text { thawed } C\left(t_{0}\right) *(1-\text { propPassive }) *\left(1-\exp ^{-\frac{t-t_{0}}{\tau}}\right)
$$


Where:

- thawedC $\left(t_{0}\right)$ is the amount of newly thawed permafrost at $t_{0}$

- propPassive is the proportion of thawed permafrost in the passive pool

- $\tau$ is the e-folding time of permafrost decomposition in the active and slow pools (i.e. not in the passive pool)

Size of the passive pool According to Burke et al. (2012; 2013), the size of this passive pool is considered uncertain and could range between $15 \%$ and $60 \%$.

Table 3: Published estimates of relative size of the passive pool

\begin{tabular}{lll}
\hline Study & $\begin{array}{l}\text { Best estimate } \\
\text { (GtC) }\end{array}$ & $\begin{array}{l}\text { Uncertainty } \\
\text { range }\end{array}$ \\
\hline Falloon et al. (1998) & $\mathrm{n} / \mathrm{a}$ & $15 \%-60 \%$ \\
Dutta et al. (2006) & $18 \%$ & $\mathrm{n} / \mathrm{a}$ \\
Burke et al. (2012) & $\mathrm{n} / \mathrm{a}$ & $18 \%-60 \%$ \\
Burke et al. (2013) & $\mathrm{n} / \mathrm{a}$ & $15 \%-60 \%$ \\
Schneider von Deimling et al. & $52.5 \%$ & $40 \%-70 \%$ \\
$(2014)$ & & \\
\hline
\end{tabular}

We take a mid-point estimate of the size of the passive pool at $40 \%$.

E-folding time of permafrost carbon decomposition The decomposition time of the thawed carbon that is not in the passive pool is considered to be in the range of 0-200 years (Burke et al., 2013). We derive an estimate of the parameter $\tau$ through existing estimates of permafrost decomposition rates, which are collected in Table 4. 
Table 4: Published estimates of the e-folding time of permafrost carbon decomposition

\begin{tabular}{|c|c|c|}
\hline Study & $\begin{array}{l}\text { e- } \\
\text { folding } \\
\text { time } \\
\text { (years) }\end{array}$ & Comments \\
\hline $\begin{array}{l}\text { Dutta et al. } \\
(2006)\end{array}$ & 20 & $\begin{array}{l}\text { Estimate based on the projection that a } 10 \% \\
\text { thaw of the yedoma stock }(46 \mathrm{GtC}) \text { would lead } \\
\text { to a total of } 40 \mathrm{GtC} \text { being transferred directly } \\
\text { or indirectly to the atmosphere four decades } \\
\text { later under a uniform temperature of } 5^{\circ} \mathrm{C} \text {. }\end{array}$ \\
\hline $\begin{array}{l}\text { Schaefer } \\
\text { et al. (2011) }\end{array}$ & 70 & $\begin{array}{l}\text { Estimate defined as the characteristic e-folding } \\
\text { time of permafrost carbon decay. }\end{array}$ \\
\hline $\begin{array}{l}\text { Elberling } \\
\text { et al. (2013) }\end{array}$ & 34-361 & $\begin{array}{l}\text { Estimate based on a three-pool dynamic model } \\
\text { that projects a potential } \mathrm{C} \text { loss between } 13 \text { and } \\
77 \% \text { for } 50 \text { years of incubation at } 5^{\circ} \mathrm{C} \text {. }\end{array}$ \\
\hline $\begin{array}{l}\text { Knoblauch } \\
\text { et al. (2013) }\end{array}$ & 167 & $\begin{array}{l}\text { Estimate calculated from turnover times of } \\
170.3 \text { years for the stable pool and } 0.26 \text { years for } \\
\text { the labile pool. }\end{array}$ \\
\hline $\begin{array}{l}\text { Schädel } \\
\text { et al. (2014) }\end{array}$ & $22-224$ & $\begin{array}{l}\text { Estimate based on projections that between } 20 \\
\text { and } 90 \% \text { of the organic } \mathrm{C} \text { will potentially be } \\
\text { mineralized to } \mathrm{CO}_{2} \text { within } 50 \text { incubation years } \\
\text { at a constant temperature of } 5^{\circ} \mathrm{C} \text {. }\end{array}$ \\
\hline $\begin{array}{l}\text { Schnei- } \\
\text { der von } \\
\text { Deimling } \\
\text { et al. }(2014)\end{array}$ & $\begin{array}{l}25(10- \\
40)\end{array}$ & $\begin{array}{l}\text { Estimate that corresponds to the turnover time } \\
\text { of an aerobic slow pool at } 5^{\circ} \mathrm{C} \text {. }\end{array}$ \\
\hline
\end{tabular}

Based on the above estimates, we assume a mean value for the parameter $\tau$ of 70 years, which, combined with the assumption that the size of the passive pool stands at c. $40 \%$, means that $31 \%$ of thawed permafrost carbon will have decomposed after 50 years. This estimate is slightly below the mean estimates from Elberling (2013) and Schädel (2014) of the percentage of total thawed carbon which has decomposed after 50 years (45\% and $55 \%$, respectively). However, their results rely on the assumption that the thawed permafrost is exposed to a constant temperature of $5^{\circ} \mathrm{C}$, which is why we adjust our estimate downwards.

Share of methane emissions Whether permafrost carbon will be released to the atmosphere in the form of $\mathrm{CO}_{2}$ or $\mathrm{CH}_{4}$ will be driven by changes in soil moisture (Natali et al., 2015). Indeed, methane is mainly produced through anaerobic decomposition, which depends on the relative saturation of the soil (Burke et al., 2012). Given the considerable uncertainty 
surrounding future changes in permafrost soil moisture, and following the approach generally used in the literature (Schuur et al., 2013; Schneider von Deimling et al., 2014), we assume that the proportion of methane emissions will remain constant until 2300. We therefore use the following equation to calculate methane emissions:

$$
C H 4 \text { emissions }(t)=\operatorname{prop} C H 4 * \operatorname{decompC}(t)
$$

Where:

- propCH4 is the (constant) share of methane emissions; and

- $\operatorname{decompC}(t)$ is the amount of decomposed carbon at time $\mathrm{t}$

There are very few published estimates of the share of methane emissions. The only two studies we are aware of which provide an explicit estimate of the percentage of permafrost carbon which will be emitted into the atmosphere as methane are the one by Schuur et al. (2013), which indicates that this proportion will be around 2.3\% and the one by Schneider von Deimling et al. (2014), which indicates that this proportion will be in the range 1.5\%$3.5 \%$. We therefore assume a mean value for the proportion of methane emissions of $2.3 \%$.

\subsection{Evaluation of the proposed modelling approach}

Figure 2 represents projected permafrost degradation based on the model described above. Shaded areas correspond to the \pm 1 standard deviation range of the $\beta$ coefficient. 
Figure 2: Projections of near-surface permafrost degradation

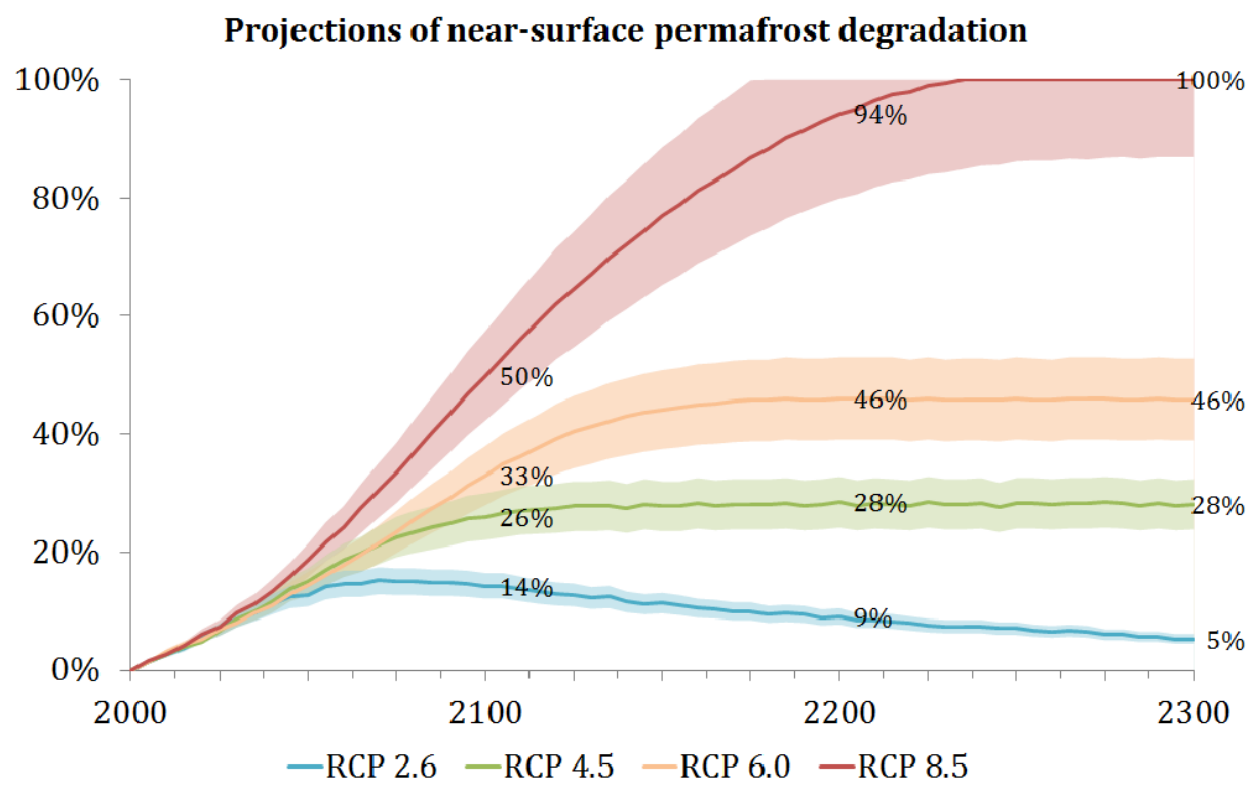

Figure 3 represents projected permafrost carbon emissions based on the model described above, assuming that: (1) the proportion of the passive pool is $40 \%$; (2) the e-folding time of permafrost in the slow and active pools is 70 years; and (3) that the proportion of methane emissions is $2.3 \%$. Shaded areas correspond to the \pm 1 standard deviation range of the $\beta$ coefficient. 
Figure 3: Projections of permafrost carbon emissions

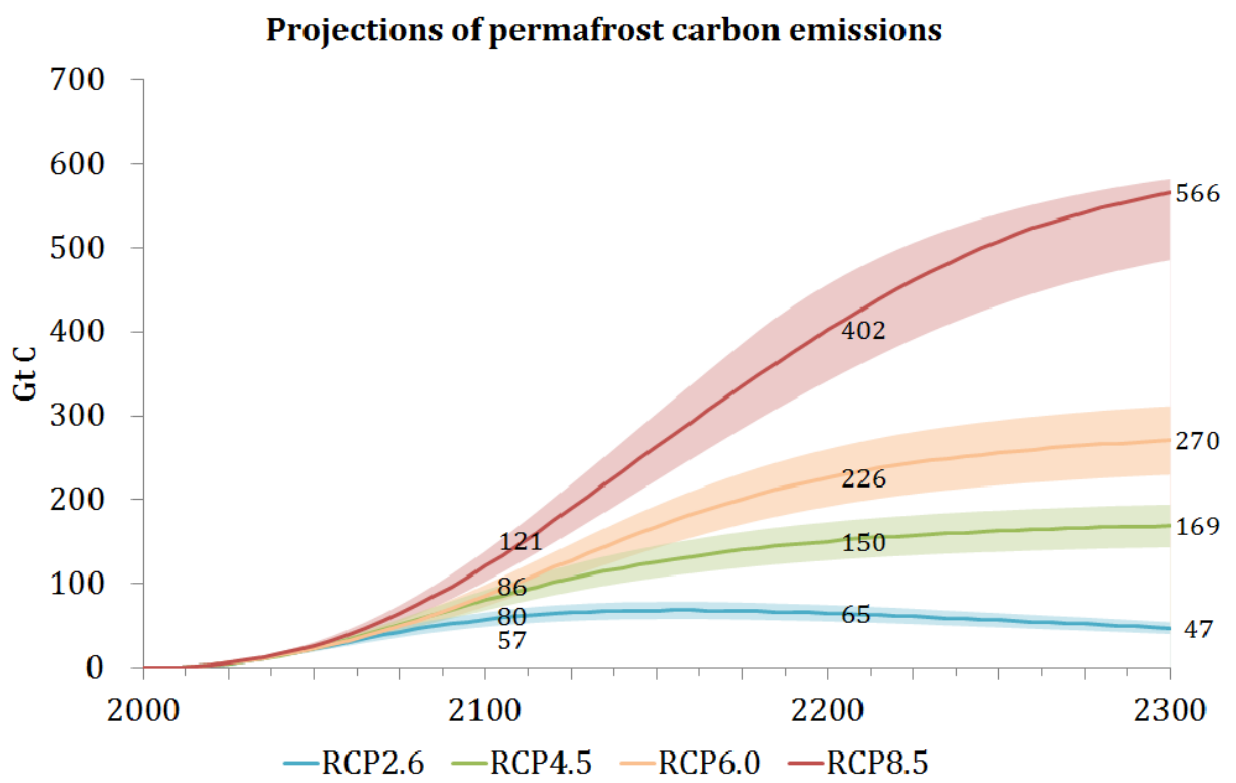

As we can see in the figure above, our model projects that cumulative permafrost carbon emissions will range between 57 and 121 GtC by 2100 , and between 47 and $566 \mathrm{GtC}$ by 2300 . This is consistent with the results of the meta-analysis done by Schaefer et al. (2014), according to which carbon emissions from thawing permafrost are likely to be in the range of 120 $\pm 85 \mathrm{GtC}$ by 2100 . It is worth noting that the only source of uncertainty considered for the graph above is the uncertainty on the beta coefficient, which represents the sensitivity of permafrost to an increase in atmospheric temperature.

\section{Results - What is the economic impact of the permafrost carbon feedback?}

This section is organised in two parts, which correspond to two different damage function specifications. We start with the assumption that damages follow the base damage function in DICE-2013R, which is a quadratic damage function. In this first part, we calculate the projected impact of the $\mathrm{PCF}$ on different physical and economic variables, we estimate the absolute and relative impact of the PCF on the SCC for different discounting parameters, we solve the model for the optimal abatement paths and we compare 
results with and without the PCF.

In the second part, we re-do these analyses under the assumption of a more convex damage function, based on the work of Weitzman (2012). There are two reasons why we decided to repeat the same set of analyses for two different damage function specifications: first, because it links the increase in atmospheric temperature to the level of climate damages, the damage function is a crucial element in IAMs, and one on which most of the results will hinge. However, the choice of a functional form for the damage function remains largely arbitrary (Pindyck, 2013). In order to account for the wide uncertainty pertaining to the relationship between future warming and damages, we thus decided to consider, for the purpose of this paper, both the commonly-used "base" quadratic damage function, and the more aggressive damage function proposed by Weitzman (2012).

\subsection{Case \#1: Quadratic damages}

\subsubsection{Impact on emissions, temperature, damages and consump- tion paths}

In this section, we use the base DICE-2013R damage function, represented by the following equation

$$
\Omega_{D I C E}(T A T M(t))=\frac{1}{1+\alpha_{1} * T A T M(t)+\alpha_{2} *(T A T M(t))^{2}}
$$

where $\alpha_{1}=0$ and $\alpha_{2}=0.002664$.

The figures below are based on the base case emissions scenario of DICE2013R and on the mean values of the uncertain parameters in the PCF module (i.e. the size of the near-surface permafrost carbon pool, the $\beta$ coefficient, the proportion of the passive pool, the e-folding time of permafrost carbon decomposition $\tau$ and the proportion of methane emissions).

Figure 4 shows the impact of the PCF on $\mathrm{CO}_{2}$ emissions, $\mathrm{CO}_{2}$ concentration, atmospheric temperature increase and consumption. 
Figure 4: Impact of the PCF on $\mathrm{CO}_{2}$ emissions, $\mathrm{CO}_{2}$ concentration, atmospheric temperature increase and consumption - assuming the DICE-2013R quadratic damage function
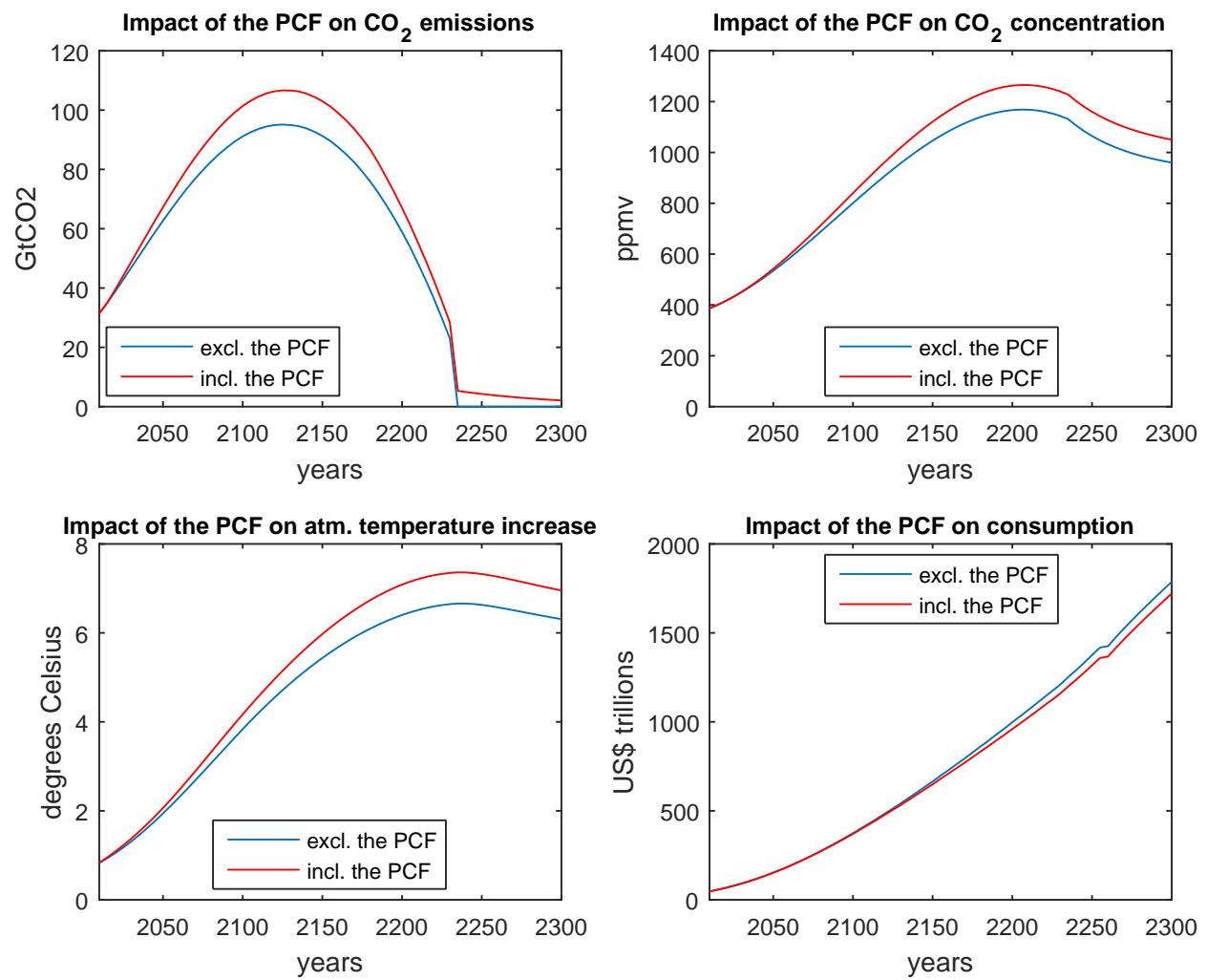

As can be seen in the figure above, the permafrost carbon feedback has an amplification effect on total $\mathrm{CO}_{2}$ emissions, which starts to become significant towards the end of the $21^{\text {st }}$ century and reaches its peak around 2150. We can also see from the graph that although industrial emissions start falling after 2130 to finally reach zero in 2235 (this corresponds to the base case scenario for the emissions control rate in DICE-2013R), $\mathrm{CO}_{2}$ emissions from thawing permafrost continue to be released in the atmosphere.

As regards the impact on $\mathrm{CO}_{2}$ concentration, the permafrost carbon feedback could add up to $97 \mathrm{ppmv}$ to the atmospheric concentration of $\mathrm{CO}_{2}$ by 2300 in the base case scenario of DICE-2013R. This is consistent with the closed-loop estimates from MacDougall et al. (2012), according to which the additional $\mathrm{CO}_{2}$ concentration due to permafrost carbon could be in the range of 53-213 ppmv (with a best estimate of $101 \mathrm{ppmv}$ ) for DEP8.5 $5^{6}$. 
As regards the effect on global mean temperature, the permafrost carbon feedback can add up to $0.70{ }^{\circ} \mathrm{C}$ to the atmospheric temperature, in the base case scenario of DICE-2013R and assuming all of the permafrost module parameters are at their mean level. This is consistent with the closed-loop estimates we have of the additional warming due to the PCF by 2300: according to MacDougall et al. (2012), the impact of the permafrost carbon feedback on atmospheric temperature could be in the range of $0.13-1.69^{\circ} \mathrm{C}$ over the period to 2300 in the DEP8.5 emissions scenario.

The cumulative (undiscounted) impact of the permafrost carbon feedback on consumption reaches $\$ 7,500$ trillion by 2300 ; this represents an average (undiscounted) impact on consumption over the period of $\$ 25$ trillion per year.

\subsubsection{Impact on the social cost of carbon}

We estimate the social cost of carbon as the net present value of the impact on consumption associated with an incremental increase in $\mathrm{CO}_{2}$ emissions in a given year. Based on this definition the base SCC for the current period (2015), calculated using DICE-2013R and for the parameter values $\rho=$ 0.015 and $\eta=1.45$ is $\$ 20.9$ per ton of $\mathrm{CO}_{2}$.

The tables below (Table 5,6 and 7) present a sensitivity analysis for the impact of the PCF on the SCC, for different levels of the pure rate of time preference $(\rho)$ and the elasticity of marginal utility $(\eta)$. These three tables correspond to three different values of the pure rate of time preference (PRTP), or utility discount rate: based on the literature, we consider the case where $\rho=0$, as advocated by Stern (2007), $\rho=0.015$ as in Nordhaus (2008) and $\rho=0.010$ as a middle-ground estimate. As regards the parameter $\eta$, which represents the elasticity of marginal utility and the intertemporal elasticity of substitution, we consider the range of [1,4]. For comparison with the result from Nordhaus (2014), we also added the case $\eta=1.45$.

\footnotetext{
${ }^{6}$ The Diagnosed Emissions Pathways (DEPs) used by MacDougall et al. (2012) are first derived from simulations of their earth system model (the UVic ESCM) driven by specific RCPs. These DEPs are then used to force the UVic ESCM, and to estimate the full impact of the PCF on the Earth's atmosphere.
} 
Table 5: Sensitivity analysis of the SCC, calculated without the PCF and assuming a quadratic damage function

\begin{tabular}{l|l|llllllll}
\hline \multicolumn{8}{c}{ SCC - without the PCF, quadratic damages } \\
\hline \multicolumn{1}{c}{} & \multicolumn{7}{c}{ Elasticity of marginal utility $\eta$} \\
\cline { 3 - 10 } PRTP $\rho$ & 1.0 & 1.45 & 1.5 & 2.0 & 2.5 & 3.0 & 3.5 & 4.0 \\
\hline & 0.000 & $\$ 204.6$ & $\$ 83.3$ & $\$ 75.9$ & $\$ 32.6$ & $\$ 16.1$ & $\$ 9.0$ & $\$ 5.6$ & $\$ 3.8$ \\
& 0.010 & $\$ 60.0$ & $\$ 30.3$ & $\$ 28.3$ & $\$ 15.0$ & $\$ 8.8$ & $\$ 5.6$ & $\$ 3.8$ & $\$ 2.7$ \\
& 0.015 & $\$ 38.0$ & $\$ 20.9$ & $\$ 19.6$ & $\$ 11.2$ & $\$ 6.9$ & $\$ 4.6$ & $\$ 3.2$ & $\$ 2.4$ \\
\hline
\end{tabular}

Table 6: Sensitivity analysis of the SCC, calculated with the PCF and assuming a quadratic damage function

\begin{tabular}{c|l|llllllll}
\hline \multicolumn{8}{c}{ SCC - with the PCF, quadratic damages } \\
\hline \multicolumn{1}{c}{} & \multicolumn{7}{c}{ Elasticity of marginal utility $\eta$} \\
\cline { 3 - 10 } PRTP $\rho$ & 1.0 & 1.45 & 1.5 & 2.0 & 2.5 & 3.0 & 3.5 & 4.0 \\
\cline { 3 - 10 } & 0.00239 .9 & $\$ 99.7$ & $\$ 91.0$ & $\$ 39.2$ & $\$ 19.2$ & $\$ 10.6$ & $\$ 6.4$ & $\$ 4.2$ \\
& 0.010 & $\$ 72.3$ & $\$ 36.4$ & $\$ 33.9$ & $\$ 17.7$ & $\$ 10.2$ & $\$ 6.3$ & $\$ 4.2$ & $\$ 3.0$ \\
& 0.015 & $\$ 45.6$ & $\$ 24.8$ & $\$ 23.2$ & $\$ 13.0$ & $\$ 7.9$ & $\$ 5.2$ & $\$ 3.6$ & $\$ 2.6$ \\
\hline
\end{tabular}

Table 7: Sensitivity analysis of the relative impact of the PCF on the SCC, assuming a quadratic damage function

\begin{tabular}{|c|c|c|c|c|c|c|c|c|c|}
\hline \multicolumn{10}{|c|}{ Relative impact of the PCF on the SCC with quadratic damages } \\
\hline & & \multicolumn{8}{|c|}{ Elasticity of marginal utility $\eta$} \\
\hline & & 1.0 & 1.45 & 1.5 & 2.0 & 2.5 & 3.0 & 3.5 & 4.0 \\
\hline \multirow{3}{*}{$\operatorname{PRTP} \rho$} & 0.000 & $17.2 \%$ & $19.7 \%$ & $19.9 \%$ & $20.4 \%$ & $19.0 \%$ & $16.7 \%$ & $14.4 \%$ & $12.3 \%$ \\
\hline & 0.010 & $20.5 \%$ & $19.9 \%$ & $19.8 \%$ & $17.9 \%$ & $15.7 \%$ & $13.6 \%$ & $11.7 \%$ & $10.2 \%$ \\
\hline & 0.015 & $20.0 \%$ & $18.6 \%$ & $18.4 \%$ & $16.3 \%$ & $14.2 \%$ & $12.3 \%$ & $10.8 \%$ & $9.5 \%$ \\
\hline
\end{tabular}

As we can see from the three tables above, accounting for the PCF when calculating the social cost of carbon increases estimates by $10-20 \%$, depending on the discounting parameters used. In Nordhaus' base case ( $\rho$ $=0.015$ and $\eta=1.45)$, the $\mathrm{SCC}$ without the $\mathrm{PCF}$ is $\$ 20.9$ per ton of $\mathrm{CO}_{2}$ whereas it reaches $\$ 24.8$ per ton of $\mathrm{CO}_{2}$ when the PCF is added to the model, which represents a $18.6 \%$ increase. This discrepancy is very similar to the one for the common "middle-ground" values of $\rho=0.010$ and $\eta=2.0$, which lead to an estimate of the SCC which is $17.9 \%$ higher in the case with the PCF compared to the case without the PCF. These results are a direct implication of the lagged nature of the PCF and emphasize the importance of discounting when it comes to estimating climate change impacts. 


\subsubsection{Impact on the optimal abatement path}

To our knowledge, we are the first to solve for optimality an Integrated Assessment Model which includes the PCF. In order to do so, we run the model in Matlab to derive the optimal emissions control rate and the optimal carbon tax which maximize a social welfare function, $W$, that is the discounted sum of the population-weighted utility of per capita consumption:

$$
W=\sum_{t=1}^{T_{\max }} U[c(t), L(t)] R(t)
$$

where:

- $U[c(t), L(t)]=L(t) *\left[\frac{c(t)^{1-\alpha}}{1-\alpha}\right]$

- $R(t)=(1+\rho)^{-t}$

For this exercice we consider that the discounting parameters are fixed with $\rho=0.015$ and $\eta=1.45$, which correspond to the DICE-2013R default settings.

The graphs below (Figure 5) display the optimal emissions control rate path and carbon price, as well as the corresponding industrial emissions and atmospheric temperature increase paths for the base case (without the PCF) and for the case in which the PCF is taken into account. We use for this exercise the optimization toolbox in Matlab. 
Figure 5: Emissions control rate, carbon tax, industrial emissions and atmospheric temperature increase in the optimal scenario - assuming a quadratic damage function
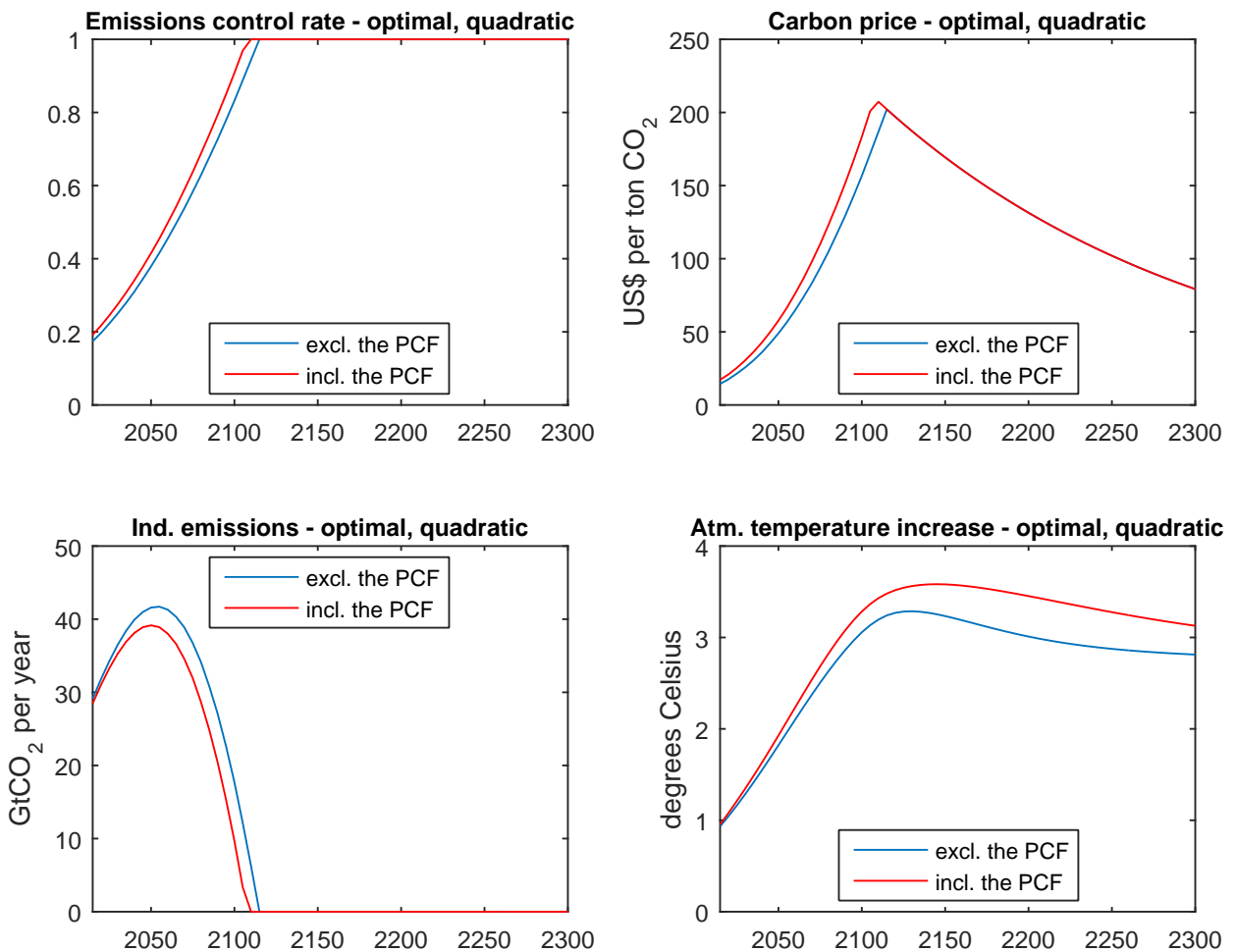

As we can see in the graphs above, the difference in the optimal emissions control rate between the case with the PCF and the case without the $\mathrm{PCF}$ can be as high as 8.1 percentage points. For instance, the optimal emissions control rate without the PCF is $37.9 \%$ in 2050 in the case without the PCF and $41.5 \%$ when the PCF is taken into consideration. By 2100, the difference has grown bigger, from an optimal emissions control rate of $83.2 \%$ in the case without the PCF and $90.8 \%$ in the case with the PCF. This translates into a c. $17.5 \%$ difference between the average optimal carbon price in the case with the PCF and the average optimal carbon price in the case without the PCF over the period 2015-2110, before the industrial emissions cease.

Similarly to the optimal $\mathrm{CO}_{2}$ industrial emissions path which was calculated by Nordhaus (2013), we find that it follows a bell-shaped curve to 2110. The area between the two curves, which represents the difference in total industrial emissions between the optimal scenario with the PCF and the optimal scenario without the PCF amounts to $390 \mathrm{GtCO}_{2}$ over the pe- 
riod 2015-2300. Finally, we find that in the optimal case without the PCF, the increase in atmospheric temperature path peaks at $3.29^{\circ} \mathrm{C}$ whereas it is slightly higher in the case with the PCF, at $3.58^{\circ} \mathrm{C}$.

\subsubsection{Impact on the optimal abatement path, with $\mathrm{a}+2{ }^{\circ} \mathrm{C}$ con- straint on atmospheric temperature increase}

Limiting atmospheric temperature increase to $2{ }^{\circ} \mathrm{C}$ above pre-industrial levels has long been presented by scientists (Rijsberman et al., 1990) as the condition to avoid the worst impacts of climate change, and has become, since the Copenhagen Accord in 2009, the internationally accepted target for climate policy. For this reason, we now run the model in optimal mode (as previously), but with the additional constraint that the increase in atmospheric temperature should not exceed $2{ }^{\circ} \mathrm{C}$. The following graphs show the optimal emissions control rate and the corresponding optimal carbon tax, as well as the industrial emissions and atmospheric temperature increase paths, for the cases with and without the PCF, when this additional constraint is added to the optimisation program. 
Figure 6: Emissions control rate, carbon tax, industrial emissions and atmospheric temperature increase in the optimal scenario - assuming a quadratic damage function and with $\mathrm{a}+2{ }^{\circ} \mathrm{C}$ constraint on temperature
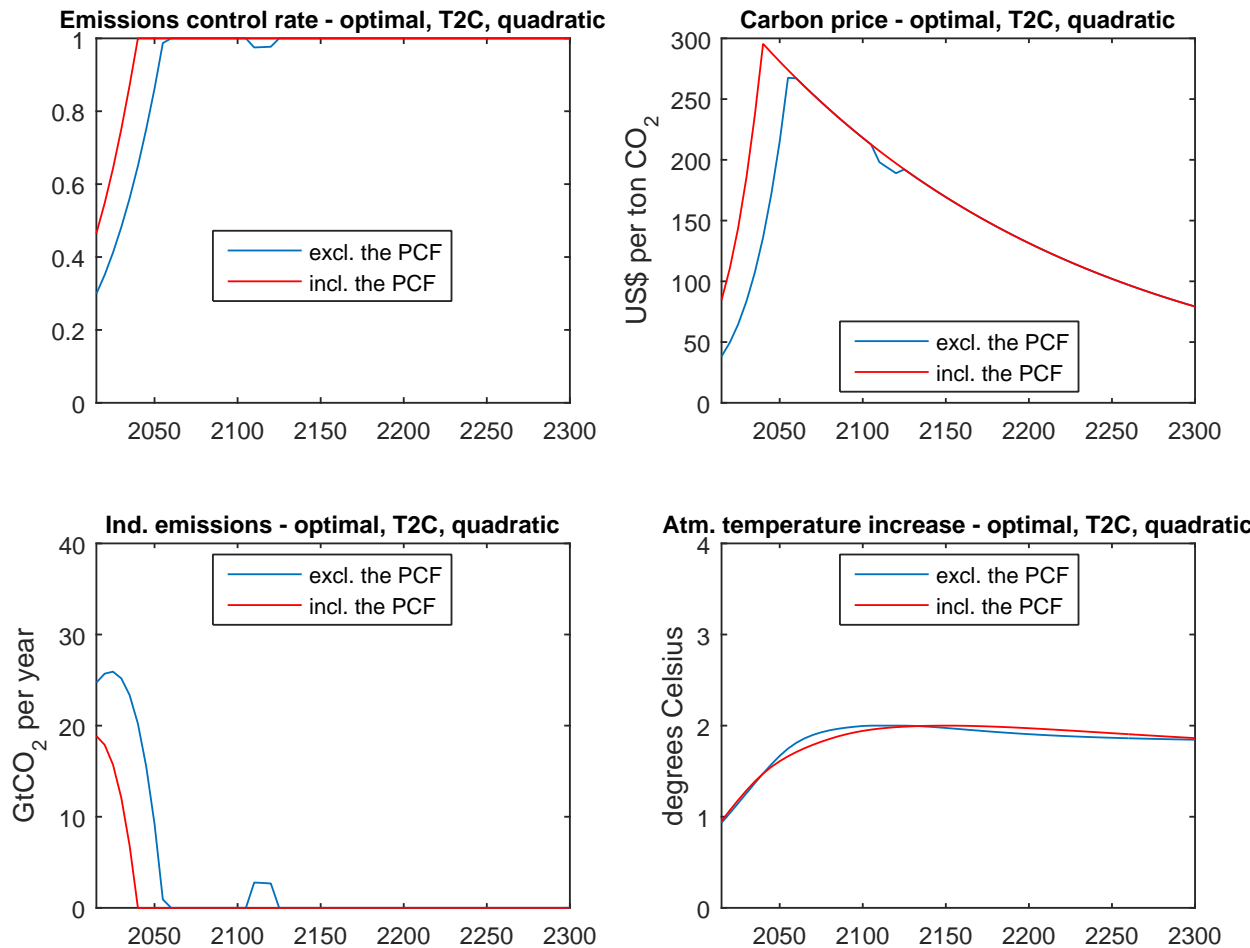

As we can see in the graphs above (Figure 6), adding the constraint of limiting the increase in atmospheric temperature to $+2{ }^{\circ} \mathrm{C}$ has a significant impact on the difference between the emissions control rate in the case without the $\mathrm{PCF}$ and in the case with the $\mathrm{PCF}^{7}$. This difference even reaches 35 percentage points in the early years of the period. It reaches its peak in 2040, when the optimal emissions control rate is $100 \%$ in the case with the $\mathrm{PCF}$ and $65.0 \%$ in the case without. This translates into a relative impact on the carbon price which is on average $92.0 \%$ over the period 2015-2055, before the emissions control rate reaches 1 .

As regards the optimal paths of industrial $\mathrm{CO}_{2}$ emissions under the $+2{ }^{\circ} \mathrm{C}$ constraint we find that cumulative emissions over the period 20152300 are, for the case without the PCF, 3,210 $\mathrm{GtCO}_{2}$ without the constraint

\footnotetext{
${ }^{7}$ There seems to be some slack in the model when the emissions control rate is no longer equal to 1 between the years 2110 and 2120. While we cannot fully account for it, the same pattern is also found in Nordhaus' results for the optimal path in the Limt2 scenario (Nordhaus, 2013).
} 
compared to $890 \mathrm{GtCO}_{2}$ with the constraint. When we take into account the impact of $\mathrm{PCF}$, these levels of cumulative industrial emissions fall to 2,820 $\mathrm{GtCO}_{2}$ without the constraint and to $360 \mathrm{GtCO}_{2}$ with the constraint. As expected, the PCF amplifies the difference between cumulative industrial emissions in the optimal scenario with no constraints and in the optimal scenario with $\mathrm{a}+2{ }^{\circ} \mathrm{C}$ constraint on atmospheric temperature increase: this difference increases from $2,320 \mathrm{GtCO}_{2}$, when the PCF is not taken into account, to 2,460 $\mathrm{GtCO}_{2}$. This supports the argument that setting a limit on atmospheric temperature increase (or atmospheric $\mathrm{CO}_{2}$ concentration) and estimating the maximum level of industrial emissions that is permitted by this target, without taking into account the projected impacts of the permafrost carbon feedback, might lead us to significantly miss the target.

The graphs below (Figure 7) chart abatement costs (relative to gross output) paths in the optimal scenario, in the case without the $+2{ }^{\circ} \mathrm{C}$ constraints on atmospheric temperature increase and in the case with the constraint. The impact of the PCF on relative abatement costs between 2015 and 2300 when there is no constraint on atmospheric temperature increase represents on average 0.12 percentage points over the period 2015-2110. When the constraint is added to the model, the impact of the PCF on relative abatement costs increases to 1.27 percentage points on average over the period 2015-2055. 
Figure 7: Abatements costs in the optimal scenario and assuming a quadratic damage function - comparing the case with and without a $+2{ }^{\circ} \mathrm{C}$ constraint on temperature
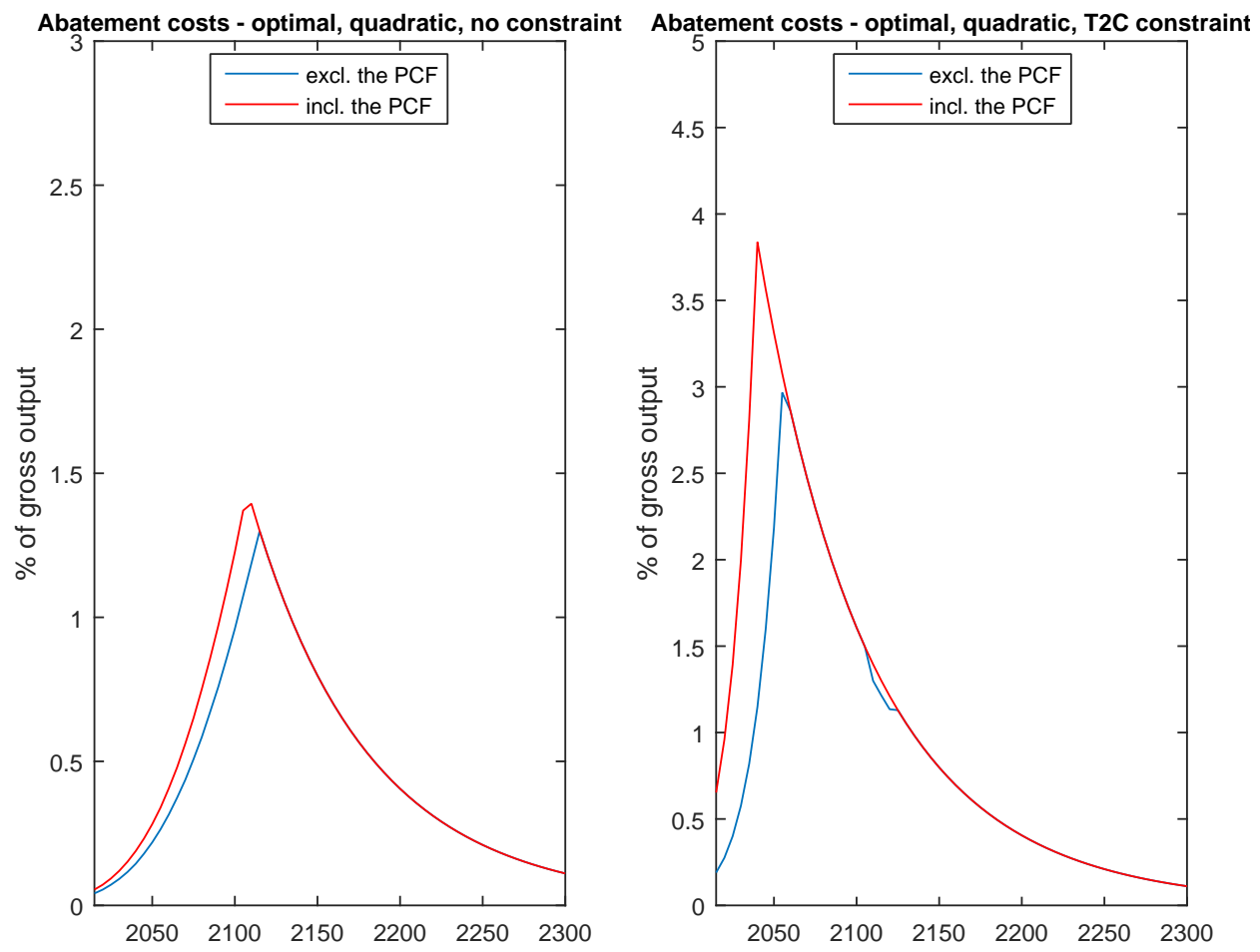

\subsection{Case \#2: Weitzman damages}

\subsubsection{Impact on emissions, temperature, damages and consump- tion paths - assuming the Weitzman damage function}

In this section, we examine the implications of the damage function specification. In order to do so we recalculate previous results using an alternative damage function, which was proposed by Weitzman (2012).

$$
\Omega_{W e i t z m a n}(T A T M(t))=\frac{1}{1+\left(\alpha_{1} * T A T M(t)\right)^{2}+\left(\alpha_{2} * T A T M(t)\right)^{\gamma}}
$$

where parameter values are the following:

- $\alpha_{1}=1 / 20.46$

- $\alpha_{2}=1 / 6.081$ 
- $\gamma=6.754$

Figure 8 shows the impact of the PCF on the increase in atmospheric temperature (TATM).

Figure 8: Impact of the $\mathrm{PCF}$ on $\mathrm{CO}_{2}$ emissions, $\mathrm{CO}_{2}$ concentration, atmospheric temperature increase and consumption - assuming the Weitzman damage function
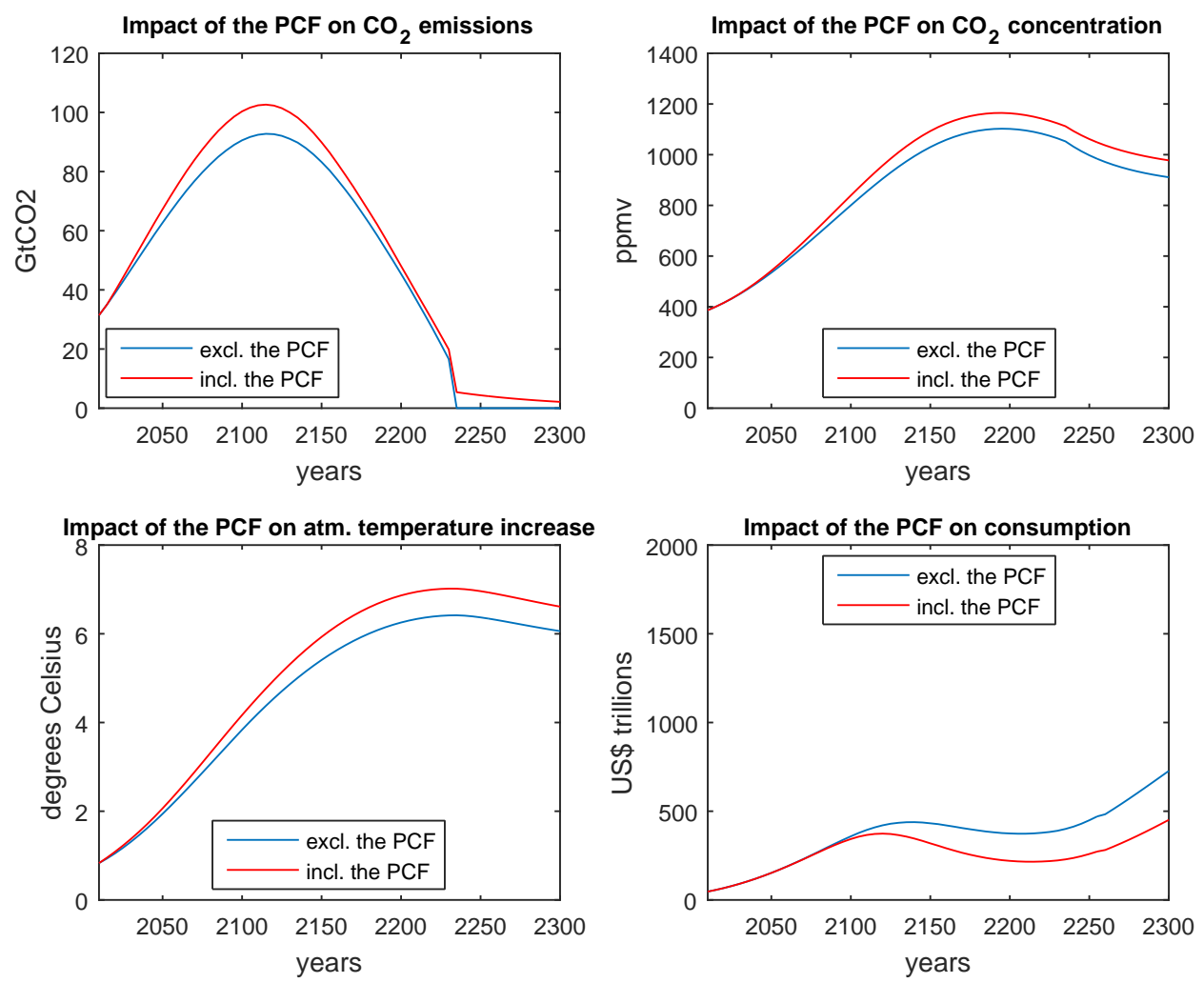

\subsubsection{Impact on the social cost of carbon - assuming the Weitz- man damage function}

We repeat the same exercise as in section 4.1.2, the only change being that we now make the assumption that the damage function follows Weitzman (2012). We consider the same ranges for parameters $\rho$ and $\eta$ as previously. 
Table 8: Sensitivity analysis of the SCC, calculated without the PCF assuming the Weitzman damage function

\begin{tabular}{|c|c|c|c|c|c|c|c|c|c|}
\hline \multicolumn{10}{|c|}{ SCC - without the PCF, Weitzman damages } \\
\hline & & \multicolumn{8}{|c|}{ Elasticity of marginal utility $\eta$} \\
\hline \multirow{4}{*}{$\operatorname{PRTP} \rho$} & & 1.0 & 1.45 & 1.5 & 2.0 & 2.5 & 3.0 & 3.5 & 4.0 \\
\hline & 0.000 & $\$ 1,676.5$ & $\$ 777.6$ & $\$ 714.6$ & $\$ 310.0$ & $\$ 137.2$ & $\$ 62.2$ & $\$ 29.1$ & $\$ 14.2$ \\
\hline & 0.010 & $\$ 338.5$ & $\$ 165.4$ & $\$ 153.0$ & $\$ 70.9$ & $\$ 33.9$ & $\$ 17.0$ & $\$ 9.0$ & $\$ 5.1$ \\
\hline & 0.015 & $\$ 173.3$ & $\$ 87.2$ & $\$ 80.9$ & $\$ 39.0$ & $\$ 19.6$ & $\$ 10.4$ & $\$ 5.9$ & $\$ 3.6$ \\
\hline
\end{tabular}

Table 9: Sensitivity analysis of the SCC, calculated with the PCF - assuming the Weitzman damage function

\begin{tabular}{c|c|cccccccc}
\hline \multicolumn{7}{c}{ SCC - with the PCF, Weitzman damages } \\
\cline { 3 - 10 } & \multicolumn{7}{c}{ Elasticity of marginal utility $\eta$} \\
\cline { 3 - 10 } PRTP $\rho$ & 1.0 & 1.45 & 1.5 & 2.0 & 2.5 & 3.0 & 3.5 & 4.0 \\
\hline & 0.000 & $\$ 1,974.5$ & $\$ 1,088.2$ & $\$ 1,019.2$ & $\$ 533.3$ & $\$ 282.8$ & $\$ 152.1$ & $\$ 82.9$ & $\$ 45.9$ \\
& 0.010 & $\$ 459.1$ & $\$ 252.7$ & $\$ 236.6$ & $\$ 124.0$ & $\$ 66.1$ & $\$ 36.0$ & $\$ 20.1$ & $\$ 11.5$ \\
& 0.015 & $\$ 245.5$ & $\$ 135.4$ & $\$ 126.9$ & $\$ 66.9$ & $\$ 36.0$ & $\$ 19.9$ & $\$ 11.4$ & $\$ 6.7$ \\
\hline
\end{tabular}

Table 10: Sensitivity analysis of the relative impact of the PCF on the SCC - assuming the Weitzman damage function

\begin{tabular}{l|lllllllll}
\hline \multicolumn{8}{c}{ Relative impact of the PCF on the SCC, Weitzman damages } \\
\cline { 3 - 10 } & & 1.0 & 1.45 & 1.5 & 2.0 & 2.5 & 3.0 & 3.5 & 4.0 \\
\cline { 3 - 10 } PRTP $\rho$ & 0.000 & $17.8 \%$ & $39.9 \%$ & $42.6 \%$ & $72.0 \%$ & $106.1 \%$ & $144.4 \%$ & $184.7 \%$ & $222.8 \%$ \\
& 0.010 & $35.6 \%$ & $52.7 \%$ & $54.7 \%$ & $74.8 \%$ & $94.8 \%$ & $112.2 \%$ & $124.0 \%$ & $127.3 \%$ \\
& 0.015 & $41.6 \%$ & $55.4 \%$ & $56.9 \%$ & $71.6 \%$ & $84.0 \%$ & $92.1 \%$ & $94.1 \%$ & $89.3 \%$ \\
\hline
\end{tabular}

As we can see from the tables above, the impact of the PCF on the social cost of carbon is much stronger in the case of the Weitzman damage function than in the case of a quadratic damage function: the effect of the PCF, which ranged between 10 and $20 \%$ in the case of quadratic damages now ranges between 18 and $220 \%$. Whereas the first analysis (with the quadratic damage function) emphasized the importance of the lagged impacts of the $\mathrm{PCF}$, the tables above demonstrate that the relative impact of the PCF on the social cost of carbon is extremely sensitive to the convexity of the damage function used in the model. Indeed, even with middle-range discounting parameters, the choice of an aggressive damage function means that the PCF could increase the social cost of carbon by more than $50 \%$. 


\subsubsection{Impact on the optimal abatement path - assuming the Weitz- man damage function}

We repeat the exercise done in section 4.1 .3 but we assume this time that climate damages follow the Weitzman damage function. As previously, we consider that the discounting parameters are fixed with $\rho=0.015$ and $\eta=$ 1.45 .

Figure 9: Emissions control rate, carbon tax, industrial emissions and atmospheric temperature increase in the optimal scenario - assuming the Weitzman damage function
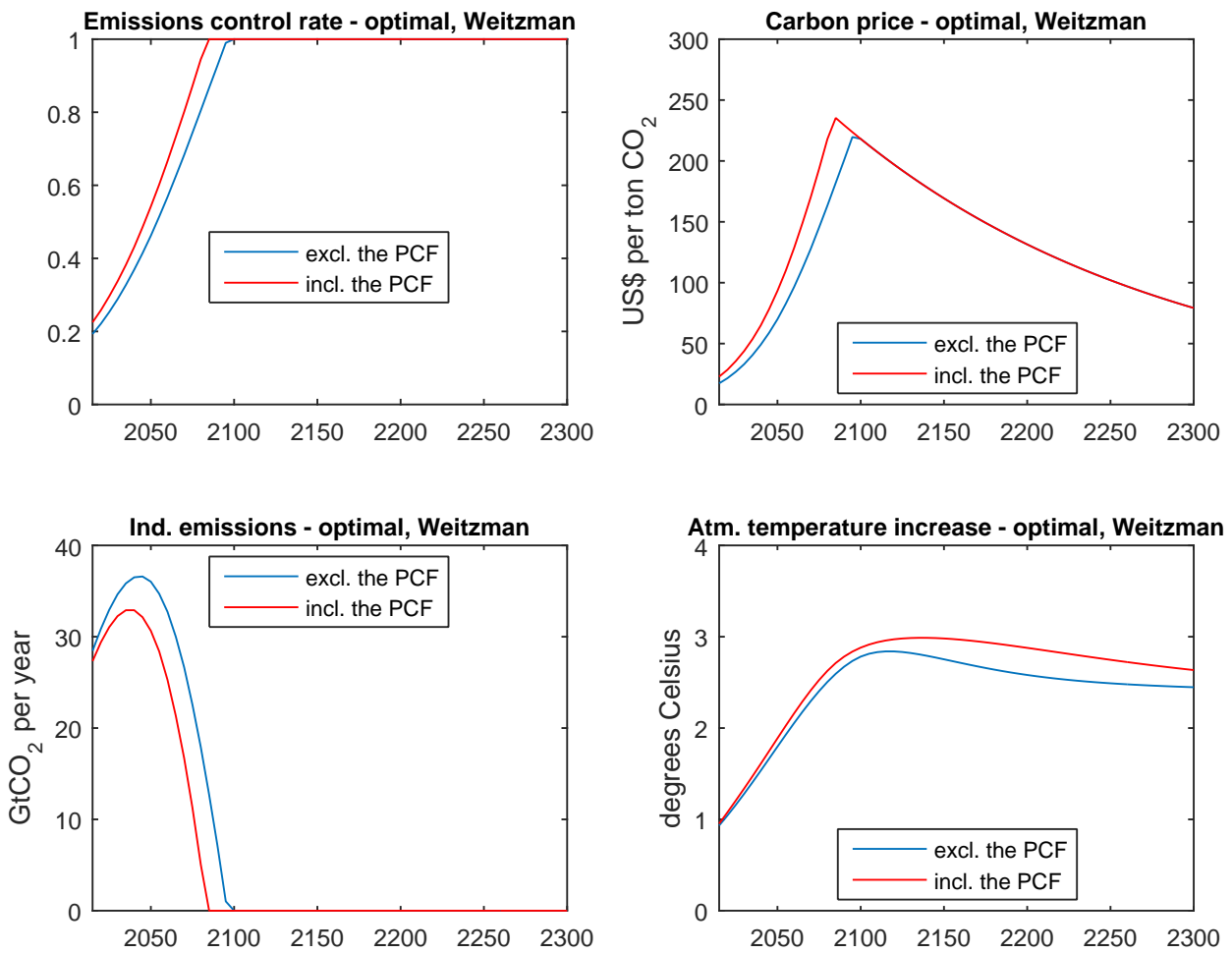

As we can see in the graphs above (Figure 9), the difference in the optimal emissions control rate between the case with the PCF and the case without the $\mathrm{PCF}$ is in the range of 1.0 to 14.0 percentage points during the period that the emissions control rate is not equal to 1 (2015-2095). This translates into a c. $30 \%$ difference between the optimal carbon price in the case with the PCF and the optimal carbon price in the case without the PCF over the period 2015-2095. 
Similarly to our findings for the quadratic damage function, we find that the optimal industrial emissions path follows a bell-shaped curve to 2095 . The area between the two curves, which represents the difference in total industrial emissions between the optimal scenario with the PCF and the optimal scenario without the PCF amounts to $500 \mathrm{GtCO}_{2}$ over the period 2015-2300, which is c. $28 \%$ higher than in the case with the quadratic damage function. Finally, we find that in the optimal case without the PCF, the increase in atmospheric temperature path peaks at $2.84^{\circ} \mathrm{C}$ whereas it is slightly higher in the case with the PCF, at $2.99^{\circ} \mathrm{C}$. These numbers reflect the stronger convexity of the Weitzman damage function compared to the base quadratic damage function used in DICE-2013R.

\subsubsection{Impact on the optimal abatement path, with $\mathrm{a}+2{ }^{\circ} \mathrm{C}$ con- straint on atmospheric temperature increase - assuming the Weitzman damage function}

We now run the second experiment in which we add the additional constraint that the increase in atmospheric temperature should not exceed $2{ }^{\circ} \mathrm{C}$. The following graphs (Figure 10) show the optimal emissions control rate and the corresponding optimal carbon tax, as well as the industrial emissions and atmospheric temperature increase paths, for the cases with and without the $\mathrm{PCF}$, when this additional constraint is added to the optimisation. 
Figure 10: Emissions control rate, carbon tax, industrial emissions and atmospheric temperature increase in the optimal scenario - assuming the Weitzman damage function and with a $2{ }^{\circ} \mathrm{C}$ constraint on temperature
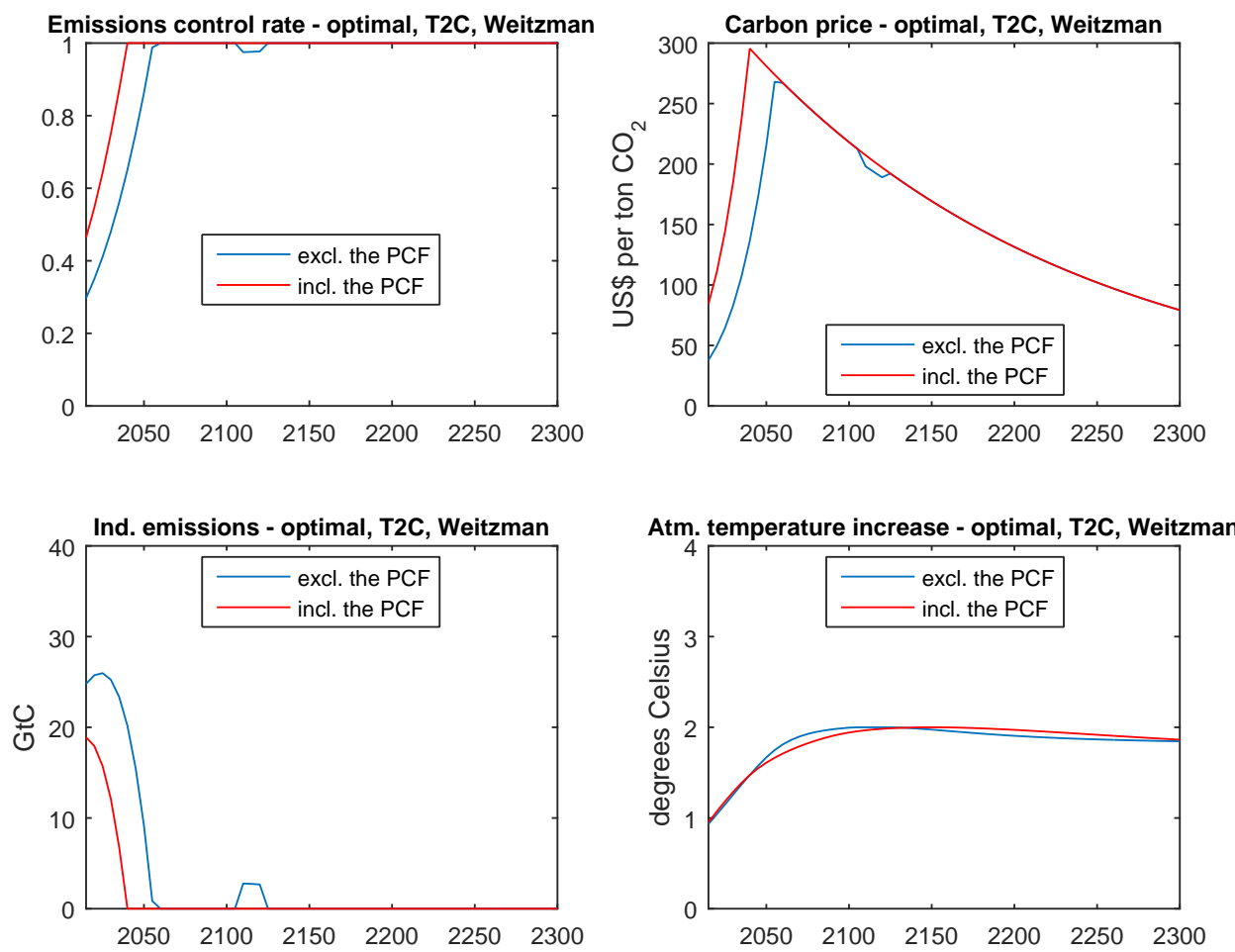

As we can see in the graphs above, adding the constraint of limiting the increase in atmospheric temperature to $+2{ }^{\circ} \mathrm{C}$ has a significant impact on the difference between the emissions control rate in the case without the $\mathrm{PCF}$ and in the case with the PCF. This difference even reaches 35 percentage points in the early years of the period, which is similar to the case of the quadratic damage function. This translates into a relative impact on the carbon price which is on average $92.3 \%$ over the period $2015-2060$, date at which the emissions control rate reaches 1 .

As regards the optimal paths of industrial $\mathrm{CO}_{2}$ emissions under the $+2{ }^{\circ} \mathrm{C}$ constraint we find that cumulative emissions over the period 20152300 are, for the case without the $\mathrm{PCF}, 2,290 \mathrm{GtCO}_{2}$ without the constraint compared to $890 \mathrm{GtCO}_{2}$ with the constraint. When we take into account the PCF these levels of cumulative industrial emissions fall to $1,780 \mathrm{GtCO}_{2}$ without the constraint vs. $360 \mathrm{GtCO}_{2}$ with the constraint. Hence, the PCF still amplifies the difference between cumulative industrial emissions between the optimal scenario with no constraints and the optimal scenario with a $+2{ }^{\circ} \mathrm{C}$ 
constraint on atmospheric temperature increase, from $1,400 \mathrm{GtCO}_{2}$ to 1,420 $\mathrm{GtCO}_{2}$, but to a lesser extent than in the case with quadratic damages, as higher convexity of the Weitzman damage function weighs significantly more on the optimal paths of industrial emissions.

The graphs below (Figure 11) chart abatement costs paths in the optimal scenario, in the case without the $+2{ }^{\circ} \mathrm{C}$ constraint on atmospheric temperature increase and in the case with the constraint. The impact of the PCF on relative abatement costs between 2015 and 2300 when there is no constraint on atmospheric temperature increase represents on average 0.27 percentage points over the period 2015-2095 (vs. 0.12 in the case of the quadratic damage function). When the constraint is added to the model, the impact of the $\mathrm{PCF}$ on relative abatement costs increases to 1.27 percentage points on average over the period 2015-2055, which is the same number as for the quadratic damage function.

Figure 11: Abatements costs in the optimal scenario and assuming the Weitzman damage function - comparing the case with and without a $+2{ }^{\circ} \mathrm{C}$ constraint on temperature
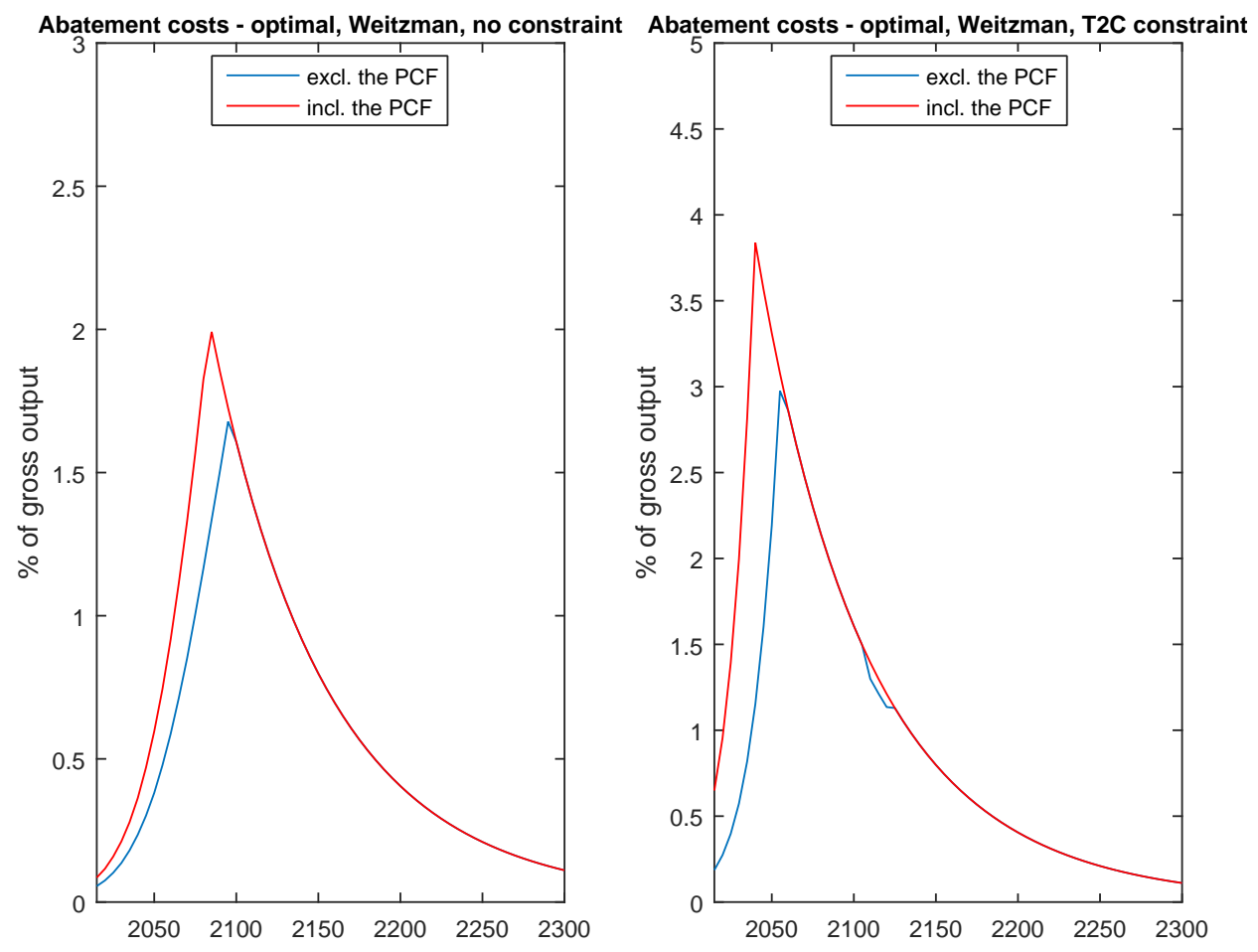


\subsection{Uncertainty analysis}

We now examine the impact of uncertainty about the PCF on the social cost of carbon. In order to do so, we assign distributions to the five main uncertainties in our modelling of the permafrost carbon feedback:

- The size of the permafrost carbon pool: according to Hugelius et al. (2014), the $95 \%$ confidence interval for the size of the permafrost carbon pool is $1,035 \pm 150$. We therefore calibrate a normal distribution based on these estimates.

- The proportion of the passive carbon pool: based on the estimates from Table 3 we make the assumption that the proportion of the passive pool follows a normal distribution with a mean of $40 \%$ and a twostandard deviation interval of $11 \%$.

- The $\beta$ coefficient: based on the estimation described in Section 3.2.1, we assume that the $\beta$ coefficient follows a normal distribution with a mean of 0.172 and a standard deviation of 0.0261 .

- The e-folding time of permafrost carbon decomposition: according to Burke et al. (2013), the decomposition time of the thawed carbon that is not in the passive pool is considered to be in the range of 0-200 years. Given the wide range of the estimates in Table 4 we assume that the e-folding time of permafrost carbon decomposition (in the active and slow pools. i.e. not considering the passive pool) follows a normal distribution with a mean of 70 and a standard deviation of 30 .

- The share of methane emissions: based on the few estimates we have of the share of methane emissions (see Section 3.2.2), we consider for this parameter a normal distribution with a mean of $2.3 \%$ and a standard deviation of $0.6 \%$.

We now conduct a Monte Carlo simulation of the model. In order to do so, we take a Latin Hypercube Sample of the parameter space and we generate 10000 draws of the model with the PCF and with the quadratic damage function. We then repeat the exercise with the Weitzman damage function. The resulting two normalized histograms for the social cost of carbon are displayed on Figure 12. 
Figure 12: SCC histogram - with uncertainty on the PCF only
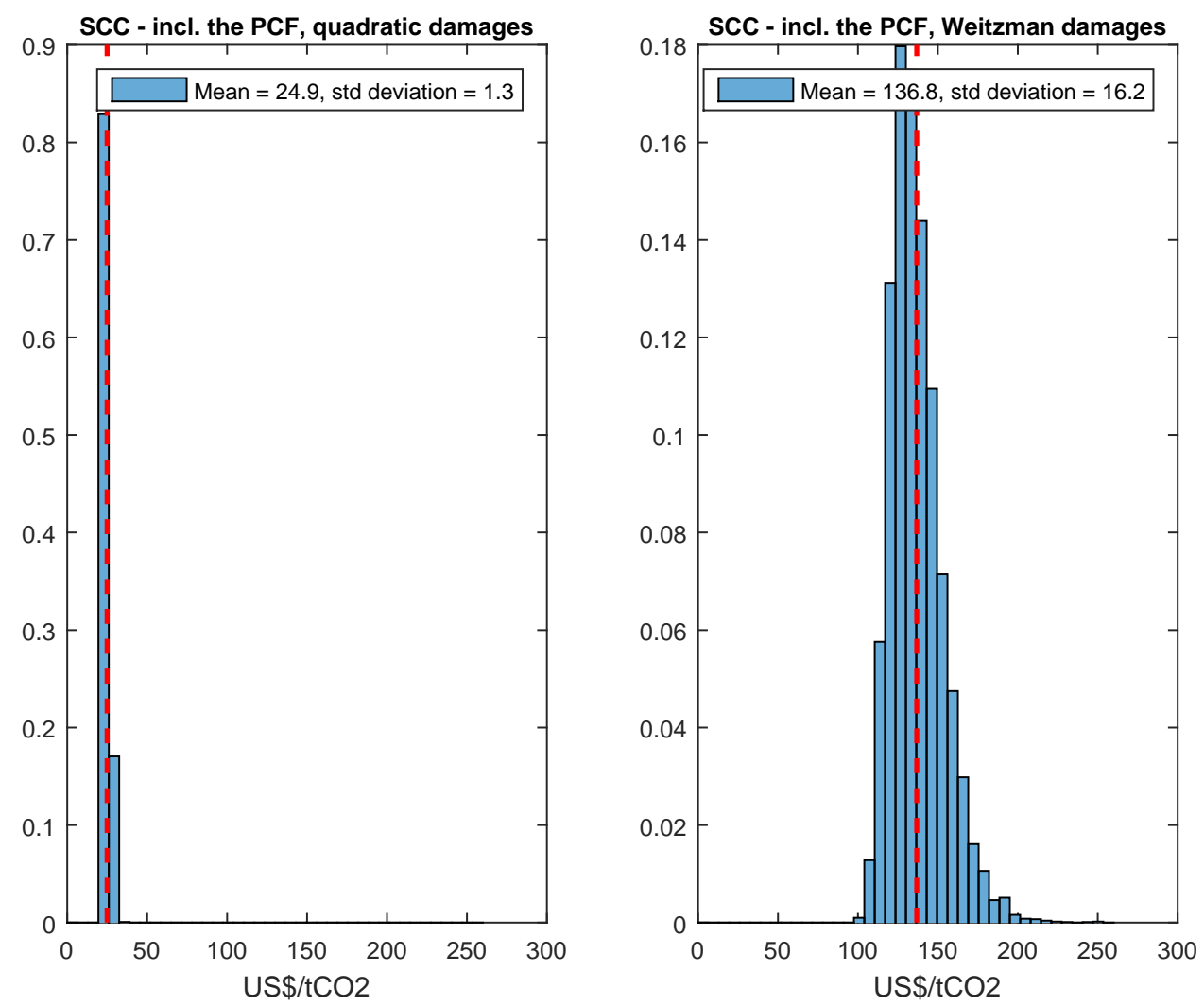

As can be seen in the chart above, the range of the social cost of carbon is much wider with the Weitzman damage function than with the base quadratic damage function used in DICE-2013R. This is a direct impliction of a higher convexity of the Weitzman damage function, which amplifies the impacts of the PCF on social welfare.

\section{Discussion}

As far as we are aware, there is only one other study which has tried to estimate the economic cost of the permafrost carbon feedback through the use of an Integrated Assessment Model, which is the recent paper by Hope and Schaefer (2015), who linked the PAGE09 IAM with the SiBCASA land surface model. It is worth noting that they only consider the A1B scenario from the Fourth Assessment Report of the IPCC (2007) in which anthropogenic emissions stop in 2100 , when the atmospheric $\mathrm{CO}_{2}$ concentration reaches $700 \mathrm{ppm}$. Therefore, all their results are based on the assumption 
that there are zero anthropogenic emissions after 2100. Most of our simulations (except the ones which solve for the optimal path) are based on the default emissions control rate of DICE-2013R in which the atmospheric concentration of carbon reaches $1,698 \mathrm{GtC}$ in 2100 , which corresponds to $800 \mathrm{ppm}$. This should explain why we find slightly larger impacts of the PCF in 2100. Notably, Hope and Schaefer (2015) find that the mean annual value of all extra impacts is about US $\$ 2.8$ trillion in 2100 and peaks at US $\$ 30$ trillion in 2200. In our base case scenario (DICE-2013R) we find that the mean annual value of the extra damages due to the PCF is about $\$ 3.6$ trillion in 2100 and increases until it reaches $\$ 57$ trillion by 2300 .

They also find that the PCF increases the mean net present value of the impacts of climate change by roughly $13 \%$. Considering that our model runs to 2300 , contrary to theirs which only runs to 2200 , and that our scenario is less optimistic than the A1B scenario on the level of future anthropogenic emissions, this number can be said to be roughly in line with our base estimate of a relative impact of the PCF on the social cost of carbon of $+18.6 \%$ (Table 7).

It is worth highlighting here that our model does not take into account the fact that thawing permafrost will also release nitrogen that is likely to offset some carbon losses through enhanced fertilization. However recent research seems to suggest that the large potential carbon losses from the permafrost region are unlikely to be compensated by the nitrogen fertilization accompanying decomposition (Koven et al., 2015a).

In fact, despite these seemingly high numbers, there are several factors which suggest that our model might significantly underestimate the economic impact of the PCF. First, there are reasons to believe that the current estimated projections of permafrost carbon thaw and decomposition are conservative (Schneider von Deimling et al., 2014) For instance, most studies do not account for the potential thaw and decomposition of deep frozen carbon outside the Yedoma and refrozen thermokarst (RTK) regions, as no coherent data is currently available on the distribution and characterization of soils below $3 \mathrm{~m}$ depth for large regions in Siberia, Alaska and Canada. Still, these depths are likely to be affected by thaw over the coming centuries, and to contribute to the permafrost carbon feedback.

Another phenomenon which is not considered in this paper is the possibility of abrupt thaw. According to Schuur et al. (2015), recent regional research seems to be suggest that a large fraction of permafrost carbon could be vulnerable to abrupt thaw, as climate change is expected to increase the initiation and expansion of abrupt thaw features. Even if abrupt thaw would only occur at point locations, there is a risk that it could cause deeper per- 
mafrost thaw to occur more rapidly. However, due to the strong uncertainty on the conditions which would cause abrupt thawing, this process is not currently considered in forecasts of permafrost carbon-climate feedbacks.

We do not consider potential pathways of abrupt methane release here either, which could be triggered by extensive permafrost degradation leaving exposed regional hydrocarbon reservoirs below the permafrost cap (Anthony et al., 2012).

Similarly, potential changes in organic chemistry are left out of the scope of this paper, despite the fact that recent research (Hodgkins et al., 2014) has examined the biogeochemistry of peat and dissolved organic matter and concluded that the impact of permafrost thaw on organic matter chemistry could intensify the predicted climate feedbacks of increasing temperatures, permafrost carbon mobilization, and hydrological changes.

Finally, as we noted earlier, our model for permafrost degradation assumes that the state at year 2000 is stable, i.e. that the level of global mean temperature in the year 2000 does not cause permafrost to thaw. In reality, most of the permafrost observatories in Russia have shown substantial warming of permafrost during the last 20 to 30 years and there is evidence that permafrost is thawing in specific landscape settings (Romanovsky et al., 2010).

\section{Conclusion}

As emphasized by Prentice et al. (2015), the permafrost carbon feedback is, on the basis of current knowledge, potentially the most important positive feedback on policy-relevant timescales that is currently not included in Earth System models. This omission should be a concern for policy makers as it could lead to a dangerous overestimation of the level of emissions that is compatible with a given $\mathrm{CO}_{2}$ concentration target.

A variety of ad hoc methods combining data and model results have produced a large range of estimates of the potential physical magnitude of this feedback, but to our knowledge, its economic impact has not yet been fully investigated. Despite the complexity of the processes involved, we used these projections to build a simplified model, which can be integrated in DICE2013R and which represents the main uncertainties at stake. We have shown in this paper that including a rough model of the permafrost carbon feedback adds on average between 10 and $20 \%$ to the current estimates of the social cost of carbon calculated using DICE-2013R. 
We have also examined the implications of the choice of a damage function on the projected impacts of the PCF. Using a damage function which is more convex than the quadratic one used in DICE-2013R could worsen significantly the economic impacts of the PCF. Moreover, by amplifying the economic impacts, it increases drastically the uncertainty on the projected effect on the social cost of carbon. It is yet another illustration of how crucial are the issues of discounting and damage functions when it comes to assessing the future impacts of climate change.

There are numerous potential improvements which could help us to better assess the economic impacts of this imperfectly known feedback: these include a more extensive knowledge of the permafrost zone as well as a better understanding of the processes which lead to permafrost thaw and carbon decomposition. Markedly, the rates of permafrost thawing and decomposition, as well as the relative proportions of methane and carbon dioxide emissions will be of considerable significance.

Finally, there are two features of the PCF that underpin our model but which do not appear explicitly in our results: its long-term path dependency and its irreversibility. More than the figures of the projected impacts of the $\mathrm{PCF}$ on the social cost of carbon, what policy makers should have in mind is that the level of industrial emissions that we allow for over the next decades will have critical implications for the amount of permafrost carbon that is released in the atmosphere over the next centuries, and for the extent of future climate change.

These findings, as well as the width of uncertainties pertaining to this feedback, call not only for further research in this field, but also for an explicit consideration in the climate policy debate. 


\section{References}

F. Ackerman, E. A. Stanton, and R. Bueno. Fat tails, exponents, extreme uncertainty: Simulating catastrophe in dice. Ecological Economics, 69(8): 1657-1665, 2010.

O. A. Anisimov, N. I. Shiklomanov, and F. E. Nelson. Global warming and active-layer thickness: results from transient general circulation models. Global and Planetary Change, 15(3):61-77, 1997.

K. M. W. Anthony, P. Anthony, G. Grosse, and J. Chanton. Geologic methane seeps along boundaries of arctic permafrost thaw and melting glaciers. Nature Geoscience, 5(6):419-426, 2012.

J. Brown, O. Ferrians Jr, J. Heginbottom, and E. Melnikov. Circum-Arctic map of permafrost and ground-ice conditions. Number 45. 1997.

E. J. Burke, I. P. Hartley, and C. D. Jones. Uncertainties in the global temperature change caused by carbon release from permafrost thawing. The Cryosphere, 6(5):1063-1076, 2012.

E. J. Burke, C. D. Jones, and C. D. Koven. Estimating the permafrostcarbon climate response in the cmip5 climate models using a simplified approach. Journal of Climate, 26(14):4897-4909, 2013.

R. Calel, D. A. Stainforth, and S. Dietz. Tall tales and fat tails: the science and economics of extreme warming. Climatic Change, pages 1-15, 2013.

M. Ceronsky, D. Anthoff, C. Hepburn, and R. S. Tol. Checking the price tag on catastrophe: the social cost of carbon under non-linear climate response. Technical report, ESRI working paper, 2011.

S. Chadburn, E. Burke, R. Essery, J. Boike, M. Langer, M. Heikenfeld, P. Cox, and P. Friedlingstein. Impact of model developments on present and future simulations of permafrost in a global land-surface model. The Cryosphere Discussions, 9(2):1965-2012, 2015.

K. Dutta, E. Schuur, J. Neff, and S. Zimov. Potential carbon release from permafrost soils of northeastern siberia. Global Change Biology, 12(12): 2336-2351, 2006.

B. Elberling, A. Michelsen, C. Schädel, E. A. Schuur, H. H. Christiansen, L. Berg, M. P. Tamstorf, and C. Sigsgaard. Long-term co2 production following permafrost thaw. Nature Climate Change, 3(10):890-894, 2013.

P. Falloon, P. Smith, K. Coleman, and S. Marshall. Estimating the size of the inert organic matter pool from total soil organic carbon content for use in the rothamsted carbon model. Soil Biology and Biochemistry, 30 (8):1207-1211, 1998. 
P. Friedlingstein, P. Cox, R. Betts, L. Bopp, W. Von Bloh, V. Brovkin, P. Cadule, S. Doney, M. Eby, I. Fung, et al. Climate-carbon cycle feedback analysis: Results from the c4mip model intercomparison. Journal of Climate, 19(14):3337-3353, 2006.

M. J. Glotter, R. T. Pierrehumbert, J. W. Elliott, N. J. Matteson, and E. J. Moyer. A simple carbon cycle representation for economic and policy analyses. Climatic Change, 126(3-4):319-335, 2014.

J. M. Gregory, C. Jones, P. Cadule, and P. Friedlingstein. Quantifying carbon cycle feedbacks. Journal of Climate, 22(19):5232-5250, 2009.

J. W. Harden, C. D. Koven, C.-L. Ping, G. Hugelius, A. David McGuire, P. Camill, T. Jorgenson, P. Kuhry, G. J. Michaelson, J. A. O'Donnell, et al. Field information links permafrost carbon to physical vulnerabilities of thawing. Geophysical Research Letters, 39(15), 2012.

S. B. Hodgkins, M. M. Tfaily, C. K. McCalley, T. A. Logan, P. M. Crill, S. R. Saleska, V. I. Rich, and J. P. Chanton. Changes in peat chemistry associated with permafrost thaw increase greenhouse gas production. Proceedings of the National Academy of Sciences, 111(16):5819-5824, 2014.

A. F. Hof, C. W. Hope, J. Lowe, M. D. Mastrandrea, M. Meinshausen, and D. P. van Vuuren. The benefits of climate change mitigation in integrated assessment models: the role of the carbon cycle and climate component. Climatic change, 113(3-4):897-917, 2012.

C. Hope and K. Schaefer. Economic impacts of carbon dioxide and methane released from thawing permafrost. Nature Climate Change, 2015.

G. Hugelius, J. Strauss, S. Zubrzycki, J. W. Harden, E. Schuur, C.-L. Ping, L. Schirrmeister, G. Grosse, G. J. Michaelson, C. D. Koven, et al. Estimated stocks of circumpolar permafrost carbon with quantified uncertainty ranges and identified data gaps. Biogeosciences, 11(23):6573-6593, 2014 .

U. IAWG. Technical support document: Social cost of carbon for regulatory impact analysis under executive order 12866. Interagency Working Group on Social Cost of Carbon, United States Government, Washington, DC, 2010 .

IPCC. Climate Change 2013: The physical science basis: Working group I contribution to the fifth assessment report of the Intergovernmental Panel on Climate Change. Cambridge University Press, 2013.

C. Knoblauch, C. Beer, A. Sosnin, D. Wagner, and E.-M. Pfeiffer. Predicting long-term carbon mineralization and trace gas production from thawing 
permafrost of northeast siberia. Global change biology, 19(4):1160-1172, 2013.

C. D. Koven, W. J. Riley, and A. Stern. Analysis of permafrost thermal dynamics and response to climate change in the cmip5 earth system models. Journal of Climate, 26(6):1877-1900, 2013.

C. D. Koven, D. M. Lawrence, and W. J. Riley. Permafrost carbonclimate feedback is sensitive to deep soil carbon decomposability but not deep soil nitrogen dynamics. Proceedings of the National Academy of Sciences, 112(12):3752-3757, 2015a. doi: 10.1073/pnas.1415123112. URL http: //www.pnas.org/content/112/12/3752. abstract.

C. D. Koven, E. Schuur, C. Schädel, T. Bohn, E. Burke, G. Chen, X. Chen, P. Ciais, G. Grosse, J. W. Harden, et al. A simplified, data-constrained approach to estimate the permafrost carbon-climate feedback. Phil. Trans. R. Soc. A, 373(2054):20140423, 2015b.

D. M. Lawrence, A. G. Slater, and S. C. Swenson. Simulation of present-day and future permafrost and seasonally frozen ground conditions in ccsm4. Journal of Climate, 25(7):2207-2225, 2012.

D. Lemoine and C. Traeger. Tipping the climate dominoes. 2014.

A. H. MacDougall, C. A. Avis, and A. J. Weaver. Significant contribution to climate warming from the permafrost carbon feedback. Nature Geoscience, 5(10):719-721, 2012.

A. L. Marten. Transient temperature response modeling in iams: the effects of over simplification on the scc. Economics: The Open-Access, OpenAssessment E-Journal, 5, 2011.

U. Mishra, J. Jastrow, R. Matamala, G. Hugelius, C. Koven, J. Harden, C. Ping, G. Michaelson, Z. Fan, R. Miller, et al. Empirical estimates to reduce modeling uncertainties of soil organic carbon in permafrost regions: a review of recent progress and remaining challenges. Environmental Research Letters, 8(3):035020, 2013.

I. Mokhov and A. Eliseev. Modeling of global climate variations in the 20th-23rd centuries with new rcp scenarios of anthropogenic forcing. In Doklady Earth Sciences, volume 443, pages 532-536. Springer, 2012.

N. Nakicenovic and R. Swart. Special report on emissions scenarios. Special Report on Emissions Scenarios, Edited by Nebojsa Nakicenovic and Robert Swart, pp. 612. ISBN 0521804930. Cambridge, UK: Cambridge University Press, July 2000., 1, 2000. 
S. M. Natali, E. A. Schuur, M. Mauritz, J. D. Schade, G. Celis, K. G. Crummer, C. Johnston, J. Krapek, E. Pegoraro, V. G. Salmon, et al. Permafrost thaw and soil moisture driving co2 and ch4 release from upland tundra. Journal of Geophysical Research: Biogeosciences, 120(3):525-537, 2015 .

W. Nordhaus. Dice-2013r model as of november 15, 2013 [online], 2013. URL http://www.econ.yale.edu/ nordhaus/homepage/ Web-DICE-2013-April.htm. Accessed: 2015-12-03.

W. Nordhaus. Estimates of the social cost of carbon: concepts and results from the dice-2013r model and alternative approaches. Journal of the Association of Environmental and Resource Economists, 1(1):273-312, 2014.

W. Nordhaus and P. Sztorc. Dice 2013r: Introduction and users manual. Technical report, Yale University, 2013.

W. D. Nordhaus. A question of balance: economic modeling of global warming, 2008.

R. S. Pindyck. Climate change policy: What do the models tell us? Technical report, National Bureau of Economic Research, 2013.

I. C. Prentice, S. Williams, and P. Friedlingstein. Biosphere feedbacks and climate change. 2015.

J. Pycroft, L. Vergano, C. Hope, D. Paci, and J. C. Ciscar. A tale of tails: Uncertainty and the social cost of carbon dioxide. Economics: the openaccess, open-assessment E-journal, 5, 2011.

F. R. Rijsberman, R. J. Swart, et al. Targets and indicators of climatic change. Stockholm Environment Institute Stockholm, 1990.

G. Roe. Feedbacks, timescales, and seeing red. Annual Review of Earth and Planetary Sciences, 37:93-115, 2009.

V. Romanovsky, D. Drozdov, N. Oberman, G. Malkova, A. Kholodov, S. Marchenko, N. Moskalenko, D. Sergeev, N. Ukraintseva, A. Abramov, et al. Thermal state of permafrost in russia. Permafrost and Periglacial Processes, 21(2):136-155, 2010.

C. Schädel, E. A. Schuur, R. Bracho, B. Elberling, C. Knoblauch, H. Lee, Y. Luo, G. R. Shaver, and M. R. Turetsky. Circumpolar assessment of permafrost c quality and its vulnerability over time using long-term incubation data. Global change biology, 20(2):641-652, 2014.

K. Schaefer, T. Zhang, L. Bruhwiler, and A. P. Barrett. Amount and timing of permafrost carbon release in response to climate warming. Tellus B, 63(2):165-180, 2011. 
K. Schaefer, H. Lantuit, V. Romanovsky, E. Schuur, et al. Policy implications of warming permafrost. Technical report, 2012.

K. Schaefer, H. Lantuit, V. E. Romanovsky, E. A. Schuur, and R. Witt. The impact of the permafrost carbon feedback on global climate. Environmental Research Letters, 9(8):085003, 2014.

T. Schneider von Deimling, M. Meinshausen, A. Levermann, V. Huber, K. Frieler, D. Lawrence, and V. Brovkin. Estimating the near-surface permafrost-carbon feedback on global warming. Biogeosciences, 9:649$665,2012$.

T. Schneider von Deimling, G. Grosse, J. Strauss, L. Schirrmeister, A. Morgenstern, S. Schaphoff, M. Meinshausen, and J. Boike. Observation-based modelling of permafrost carbon fluxes with accounting for deep carbon deposits and thermokarst activity. Biogeosciences Discussions, 11(12): 16599-16643, 2014.

E. Schuur, B. Abbott, W. Bowden, V. Brovkin, P. Camill, J. Canadell, J. Chanton, F. Chapin III, T. Christensen, P. Ciais, et al. Expert assessment of vulnerability of permafrost carbon to climate change. Climatic Change, 119(2):359-374, 2013.

E. Schuur, A. McGuire, C. Schädel, G. Grosse, J. Harden, D. Hayes, G. Hugelius, C. Koven, P. Kuhry, D. Lawrence, et al. Climate change and the permafrost carbon feedback. Nature, 520(7546):171-179, 2015.

E. A. Schuur, J. Bockheim, J. G. Canadell, E. Euskirchen, C. B. Field, S. V. Goryachkin, S. Hagemann, P. Kuhry, P. M. Lafleur, H. Lee, et al. Vulnerability of permafrost carbon to climate change: Implications for the global carbon cycle. BioScience, 58(8):701-714, 2008.

E. A. Schuur, J. G. Vogel, K. G. Crummer, H. Lee, J. O. Sickman, and T. E. Osterkamp. The effect of permafrost thaw on old carbon release and net carbon exchange from tundra. Nature, 459(7246):556-559, 2009.

A. G. Slater and D. M. Lawrence. Diagnosing present and future permafrost from climate models. Journal of Climate, 26(15):5608-5623, 2013.

S. Solomon, D. Qin, M. Manning, Z. Chen, M. Marquis, K. Averyt, M. Tignor, and H. Miller. Ipcc, climate change 2007: the physical science basis. contribution of working group i to the fourth assessment report of the intergovernmental panel on climate change, 2007.

N. Stern. The economics of climate change: the Stern review. cambridge University press, 2007. 
N. Stern. The structure of economic modeling of the potential impacts of climate change: grafting gross underestimation of risk onto already narrow science models. Journal of Economic Literature, 51(3):838-859, 2013.

C. Tarnocai, J. Canadell, E. Schuur, P. Kuhry, G. Mazhitova, and S. Zimov. Soil organic carbon pools in the northern circumpolar permafrost region. Global biogeochemical cycles, 23(2), 2009.

D. P. van Vuuren, J. Lowe, E. Stehfest, L. Gohar, A. F. Hof, C. Hope, R. Warren, M. Meinshausen, and G.-K. Plattner. How well do integrated assessment models simulate climate change? Climatic Change, 104(2): 255-285, 2011.

R. Warren, M. D. Mastrandrea, C. Hope, and A. F. Hof. Variation in the climatic response to sres emissions scenarios in integrated assessment models. Climatic change, 102(3-4):671-685, 2010.

M. L. Weitzman. Ghg targets as insurance against catastrophic climate damages. Journal of Public Economic Theory, 14(2):221-244, 2012.

G. Whiteman, C. Hope, and P. Wadhams. Climate science: Vast costs of arctic change. Nature, 499(7459):401-403, 2013.

M. Winton. Do climate models underestimate the sensitivity of northern hemisphere sea ice cover? Journal of Climate, 24(15):3924-3934, 2011.

Q. Zhuang, J. M. Melack, S. Zimov, K. M. Walter, C. L. Butenhoff, and M. A. K. Khalil. Global methan emissions from wetlands, rice paddies, and lakes. Eos, Transactions American Geophysical Union, 90(5):37-38, 2009 . 


\section{A Appendix: Estimates of permafrost degrada- tion}

Table 11: Published estimates of future permafrost degradation

\begin{tabular}{|c|c|c|c|}
\hline \multirow[t]{2}{*}{ Study } & \multicolumn{3}{|c|}{ Permafrost area degradation } \\
\hline & 2100 & 2200 & 2300 \\
\hline \multicolumn{4}{|l|}{ RCP2.6 } \\
\hline Burke et al. (2012) & $16 \%$ & $\mathrm{n} / \mathrm{a}$ & $\mathrm{n} / \mathrm{a}$ \\
\hline Lawrence et al. (2012) & $30 \%$ & $\mathrm{n} / \mathrm{a}$ & $\mathrm{n} / \mathrm{a}$ \\
\hline Mokhov and Eliseev (2012) & $38 \%$ & $33 \%$ & $22 \%$ \\
\hline Koven et al. (2013) & $23 \%$ & $\mathrm{n} / \mathrm{a}$ & $\mathrm{n} / \mathrm{a}$ \\
\hline Schuur et al. $(2013)^{*}$ & $15 \%$ & $\mathrm{n} / \mathrm{a}$ & $25 \%$ \\
\hline Slater and Lawrence (2013) & $37 \%$ & $\mathrm{n} / \mathrm{a}$ & $\mathrm{n} / \mathrm{a}$ \\
\hline \multicolumn{4}{|l|}{ DEP2.6 } \\
\hline MacDougall et al. (2012) & $38 \%$ & $38 \%$ & $36 \%$ \\
\hline Schneider von Deimling et al. $(2012)^{*}$ & $15 \%$ & $15 \%$ & $14 \%$ \\
\hline Schneider von Deimling et al. $(2014)^{*}$ & $17 \%$ & $\mathrm{n} / \mathrm{a}$ & $\mathrm{n} / \mathrm{a}$ \\
\hline \multicolumn{4}{|l|}{$\mathrm{RCP} 4.5$} \\
\hline Burke et al. (2012) & $24 \%$ & $\mathrm{n} / \mathrm{a}$ & $\mathrm{n} / \mathrm{a}$ \\
\hline Harden et al. $(2012)^{*}$ & $23 \%$ & $\mathrm{n} / \mathrm{a}$ & $\mathrm{n} / \mathrm{a}$ \\
\hline Lawrence et al. (2012) & $49 \%$ & $\mathrm{n} / \mathrm{a}$ & $\mathrm{n} / \mathrm{a}$ \\
\hline Mokhov and Eliseev (2012) & $48 \%$ & $59 \%$ & $59 \%$ \\
\hline Koven et al. (2013) & $46 \%$ & $\mathrm{n} / \mathrm{a}$ & $\mathrm{n} / \mathrm{a}$ \\
\hline Schuur et al. $(2013)^{*}$ & $24 \%$ & $\mathrm{n} / \mathrm{a}$ & $39 \%$ \\
\hline Slater and Lawrence (2013) & $52 \%$ & $\mathrm{n} / \mathrm{a}$ & $\mathrm{n} / \mathrm{a}$ \\
\hline \multicolumn{4}{|l|}{ DEP4.5 } \\
\hline MacDougall et al. (2012) & $46 \%$ & $53 \%$ & $57 \%$ \\
\hline Schneider von Deimling et al. $(2012)^{*}$ & $26 \%$ & $35 \%$ & $38 \%$ \\
\hline Schneider von Deimling et al. (2014)* & $\mathrm{n} / \mathrm{a}$ & $\mathrm{n} / \mathrm{a}$ & $\mathrm{n} / \mathrm{a}$ \\
\hline \multicolumn{4}{|l|}{ RCP6.0 } \\
\hline Burke et al. (2012) & $27 \%$ & $\mathrm{n} / \mathrm{a}$ & $\mathrm{n} / \mathrm{a}$ \\
\hline Lawrence et al. (2012) & $56 \%$ & $\mathrm{n} / \mathrm{a}$ & $\mathrm{n} / \mathrm{a}$ \\
\hline Mokhov and Eliseev (2012) & $60 \%$ & $81 \%$ & $83 \%$ \\
\hline Koven et al. (2013) & $\mathrm{n} / \mathrm{a}$ & $\mathrm{n} / \mathrm{a}$ & $\mathrm{n} / \mathrm{a}$ \\
\hline Schuur et al. $(2013)^{*}$ & $42 \%$ & $\mathrm{n} / \mathrm{a}$ & $56 \%$ \\
\hline Slater and Lawrence (2013) & $63 \%$ & $\mathrm{n} / \mathrm{a}$ & $\mathrm{n} / \mathrm{a}$ \\
\hline \multicolumn{4}{|l|}{ DEP6.0 } \\
\hline MacDougall et al. (2012) & $49 \%$ & $58 \%$ & $63 \%$ \\
\hline Schneider von Deimling et al. $(2012)^{*}$ & $33 \%$ & $55 \%$ & $62 \%$ \\
\hline Schneider von Deimling et al. $(2014)^{*}$ & $\mathrm{n} / \mathrm{a}$ & $\mathrm{n} / \mathrm{a}$ & $\mathrm{n} / \mathrm{a}$ \\
\hline
\end{tabular}

Continued on next page 
Continued from previous page

\begin{tabular}{llll}
\hline Study & 2100 & 2200 & 2300 \\
\hline \hline RCP8.5 & & & \\
\hline Burke et al. (2012) & $35 \%$ & n/a & n/a \\
Harden et al. (2012) & $41 \%$ & n/a & n/a \\
Lawrence et al. (2012) & $76 \%$ & n/a & n/a \\
Mokhov and Eliseev (2012) & $84 \%$ & $93 \%$ & $93 \%$ \\
Koven et al. (2013) & $76 \%$ & n/a & n/a \\
Schuur et al. (2013)* & $57 \%$ & n/a & $74 \%$ \\
Slater and Lawrence (2013) & $87 \%$ & n/a & n/a \\
Chadburn et al. (2015)* & $50 \%$ & n/a & n/a \\
\hline DEP8.5 & \multicolumn{3}{|l}{} \\
\hline MacDougall et al. (2012) & $52 \%$ & $63 \%$ & $69 \%$ \\
Schneider von Deimling et al. (2012)* & $57 \%$ & $100 \%$ & $100 \%$ \\
Schneider von Deimling et al. $(2014)^{*}$ & $37 \%$ & n/a & $58 \%$ \\
\hline
\end{tabular}

The estimates marked with an asterisk $(*)$ have not been used in the regression, usually because of a lack of continuous data. 